Research Article

\title{
Impacts of Cyclic Loading and Unloading Rates on Acoustic Emission Evolution and Felicity Effect of Instable Rock Mass
}

\author{
Mingwei Zhang $\mathbb{D},{ }^{1}$ Qingbin Meng $\mathbb{D},{ }^{1}$ Shengdong Liu $\left(\mathbb{D},{ }^{1}\right.$ Deyu Qian $(\mathbb{D})^{2}$ \\ and Nong Zhang $\mathbb{D}^{2}$ \\ ${ }^{1}$ State Key Laboratory for Geomechanics and Deep Underground Engineering, School of Mechanics and Civil Engineering, \\ China University of Mining and Technology, Xuzhou, Jiangsu 221116, China \\ ${ }^{2}$ School of Mines, China University of Mining and Technology, Xuzhou, Jiangsu 221116, China
}

Correspondence should be addressed to Shengdong Liu; vipshengdongliu@sina.com

Received 23 November 2017; Accepted 2 April 2018; Published 29 April 2018

Academic Editor: Yee-wen Yen

Copyright (c) 2018 Mingwei Zhang et al. This is an open access article distributed under the Creative Commons Attribution License, which permits unrestricted use, distribution, and reproduction in any medium, provided the original work is properly cited.

Uniaxial cyclic loading-unloading compression experiments with schemes of six loading rates and six unloading rates were carried out on the combined testing platform. Impact of loading and unloading rates on rock AE characteristics was revealed. Results show that increasing loading and unloading rates resulted in decreasing total AE rings in the entire rock deformation and failure process. Increasing loading rate decreased the $\mathrm{AE}$ rings at loading stages, and increasing unloading rate decreased the $\mathrm{AE}$ rings at unloading stages in the same cycle. Total AE counts had a negative linear relationship to the loading and unloading rates. The loading stage was the active period of the AE phenomena, and impacts of the loading rate on the AE characteristics were more apparent. Especially when the loading rate was greater than $2.0 \mathrm{kN} / \mathrm{s}$, brittle failure of rock specimens became noticeable. After the cyclic load reached the uniaxial compressive strength of 1/3 1/2 times, the rock Felicity effect became more obvious. With the increase of the loading rate, the Felicity ratio decreased in the elastic stage and increased a little in the plastic stage, whereas with the increase of the unloading rate, the Felicity ratio decreased gradually in the elastic stage and remained almost the same in the plastic stage.

\section{Introduction}

Acoustic emission (AE) is a physical phenomenon that occurs when materials release elastic waves during the deformation and failure caused by external forces $[1,2]$. For rock materials, when deforming as the external force, stress concentration occurs surrounding internal cracks. Some fractures produce the yield deformation when force increases to a certain extent, extend and connect subsequently, and then induce the stress relaxation [3]. The accumulated internal energy releases suddenly in the form of elastic waves, thus resulting in the AE phenomenon. Scholars have made abundant researches on rock $\mathrm{AE}$ characteristics during the deformation and failure process [4-7]. Lavrov [8] observed the Kaiser effect in a brittle limestone cyclically loaded with different loading rates and found that damage formed in rock at a high loading rate can hardly be revealed by reloading with slow rate, yet the damage formed during loading with slow rate can be successfully revealed by using fast reloading. Nikolenko and Shkuratnik [9] found that the load application angle has significant influence on the AE memory effect up to its complete vanishing. Fan et al. [10] conducted the fatigue tests of salt rock with discontinuous cyclic loading path containing zero loading stress intervals (ZLIs) of different duration and found that $\mathrm{AE}$ evolution was very strongly dependent on the ZLI length and increased with its growth as does the residual nominal strain. It is observed that $\mathrm{AE}$ phenomena directly reflect the internal structural variation of loaded rock materials in the compression deformation and failure process.

Instability failure of rock mass is a dynamic evolution from spatial development and compaction of internal original fractures, expansion and connection of induced cracks, to readjustment of the fracture faces and structures [11]. For this reason, explaining the evolution laws of rock failure and damage based on $\mathrm{AE}$ activities has become an important mean to study the dynamic instability mechanism of rock mass from 
the mesoscale, meanwhile, has been applied into the underground engineering [12]. To accurately evaluate the danger from rock bursts during coal mining, Huang and Liu [13] carried out the uniaxial compression tests of composed coal rock at different loading rates to explore the effect of loading rate on the behaviors of rock specimens. Lukaszewski [14] described the development of fracture processes in selected Carboniferous rocks from the Upper Silesian Coal Basin with particular regard to the behaviors of rock specimens in the postfailure stage and observed the energy accumulation and dissipation phenomena during rock loading. Zhao and Jiang [15] investigated the acoustic and thermal infrared radiation characteristics of bump-prone coal under uniaxial compression and cyclic loading conditions and collected the precursory information for impending failure of coal specimens. $\mathrm{AE}$ activities are closely related with structural damage and bearing capacity of rock masses, exhibiting some certain laws in the evolution of rock dynamic instability. AE technique is gradually applied into the geomechanical disaster prevention.

In the underground engineering of coal mining, due to the influence of serious excavation, effects of high in situ stress on the rock mass in a specific region are not always exerted all at once. Especially in the km-depth mining stage in East China, geological environment gets changeable and complicated, anisotropism of surrounding rock structures on working face is quite apparent, and stress distribution in rock stratum is extremely irregular [16]. Accumulation and transferring behaviors of the high in situ stress in rock mass are gradually reciprocating. That is, stress periodic action is a kind of cyclic loading-unloading mode with respect to the rock mass, which thus makes the stress action speed, after stress magnitude, and stress action mode become other primary disadvantageous factors that seriously influence the stability control of rock masses in deep mining conditions. Adverse effects of the periodic stress action speed result in (a) the sharp growth of working resistance of hydraulic supports, thus causing local supports crushing and losing efficacy; (b) the sudden fracture and falling of rock roof, thus threatening the life and property safety of mining workers. Injuries caused by roof falling between hydraulic supports occur occasionally; (c) serious impact force as well as strong vibration, thus causing the large deformation of surrounding rock structures; and (d) the fatigue damage of underground infrastructures, such as mine refuge chamber, material warehouse, and so on. Deep coal mining is now challenged by the periodic high stress [17-19].

Therefore, researching on the impacts of periodic stress action on rock $\mathrm{AE}$ activities is significant for the rock stability control. Stress acting forms such as the periodicity, timeliness, and speed induce specific AE phenomena. Since the close relation between the fracture development in rock failure and the $\mathrm{AE}$ activities, rock $\mathrm{AE}$ characteristics under uniaxial cyclic loads have been widely investigated in recent years. Yuan and Li [20] analyzed the mechanism of the Kaiser effect under cyclic loading based on statistic damage mechanics and implied that the heterogeneity of rock was the real reason that caused irrecoverable damage on the AE Kaiser effect in cyclic loading. By focusing on the heterogeneity of rock material, Wang et al. [21] found that, based on the different AE characteristics at stable fracture propagation stage, the accelerative cracking point was located between the fracture initiation strength and critical energy release point that causes a fatal uncontrolled fracture in materials. To assess the reliability of the Kaiser effect method in measuring tensile stress, Fu et al. [22] applied the cyclic loading-unloading compression with increasing peak stress to marble specimens to conduct Brazilian and bending tests. Meng et al. [23] explored the characteristics of energy accumulation, evolution, and dissipation in uniaxial cyclic loading and unloading compression of 30 sandstone rock specimens under six different loading rates and revealed the energy evolution of rock deformation and failure.

However, related researches on the respective impacts of cyclic loading rates and unloading rates on rock $\mathrm{AE}$ activities are relatively rare, and differences in rock stability among multiple combinations of loading rates and unloading rates are little involved. Hence, to systematically explore the relation between the periodic stress action speed and the AE activities of surrounding rock structures, in this study, a uniaxial cyclic loading and unloading compression experiment using 55 red sandstone specimens under 11 loading and unloading rates was conducted. AE evolution throughout the deformation and failure process of rock specimens was achieved. Impacts of loading rates and unloading rates on rock $\mathrm{AE}$ characteristics and Felicity effect were analyzed. Relations between rock dynamic instability and periodic $\mathrm{AE}$ performances were revealed. This research aims to enhance stability control of surrounding rock masses under high periodic stress conditions and to improve the effectiveness of prediction and early warning on deep dynamic disasters (roof caving, rock burst, coal and gas outburst, etc.) using the AE technique.

\section{Experimental Investigation on AE Characteristics of Red Sandstone Specimens under Uniaxial Cyclic Loading and Unloading Compressions}

To explore the impacts of loading rate Lr and unloading rate $\mathrm{Ur}$ on rock $\mathrm{AE}$ characteristics under uniaxial cyclic loadingunloading compression conditions, six loading rates and six unloading rates $(0.5 \mathrm{kN} / \mathrm{s}, 1.0 \mathrm{kN} / \mathrm{s}, 1.5 \mathrm{kN} / \mathrm{s}, 2.0 \mathrm{kN} / \mathrm{s}, 3.0 \mathrm{kN} / \mathrm{s}$, and $4.0 \mathrm{kN} / \mathrm{s}$ ) were set in this experiment, forming a total of 11 different cyclic loading-unloading schemes. Each scheme repeated for five times and 55 rock specimens were used. Experimental programs are shown in Tables 1 and 2.

Red sandstone specimens $(\Phi 50 \mathrm{~mm} \times 100 \mathrm{~mm})$ with maroon appearance, fine structure, and uniform texture were used in the experiment. Before the tests, all specimens were put static in a constant-temperature $\left(77^{\circ} \mathrm{F}\right)$ and constanthumidity $(23 \% \mathrm{RH})$ incubator for 60 days. The average density and saturation of rock specimens were measured $2.59 \mathrm{~g} / \mathrm{cm}^{3}$ and $18.9 \%$, respectively. During the tests, axial force-controlled uniaxial compression was adopted to each rock specimen during the cyclic loading-unloading process. Based on the uniaxial compressive strength (UCS) of red sandstone specimens, $20 \mathrm{kN}, 40 \mathrm{kN}, 60 \mathrm{kN}, 80 \mathrm{kN}, 100 \mathrm{kN}$, and $120 \mathrm{kN}$ were chosen as the cyclic unloading points successively. After finishing the cyclic loading-unloading process, displacementcontrolled uniaxial compression $(\mathrm{Lr}=0.003 \mathrm{~mm} / \mathrm{s}$ ) was 
TABLE 1: Experimental scheme of impacts of uniaxial cyclic loading rates on rock AE characteristics.

\begin{tabular}{lccccc}
\hline $\begin{array}{l}\text { Unloading rate } \\
\text { Loading rate }\end{array}$ & $0.5 \mathrm{kN} / \mathrm{s}$ & $1.0 \mathrm{kN} / \mathrm{s}$ & $1.5 \mathrm{kN} / \mathrm{s}$ & $0.5 \mathrm{kN} / \mathrm{s}$ \\
\hline Rock index & $1 \#, 2 \#, 3 \#, 4 \#, 5 \#$ & $6 \#, 7 \#, 8 \#, 9 \#, 10 \# \begin{array}{c}11 \#, 12 \#, 13 \#, \\
14 \#, 15 \#\end{array}$ & $16 \#, 17 \#, 18 \#, 19 \#, 20 \#$ & $21 \#, 22 \#, 23 \#, 24 \#, 25 \# \begin{array}{c}26 \#, 27 \#, 28 \#, \\
29 \#, 30 \#\end{array}$ \\
\hline
\end{tabular}

TABLE 2: Experimental scheme of impacts of uniaxial cyclic unloading rates on rock AE characteristics.

\begin{tabular}{|c|c|c|c|c|c|c|}
\hline Loading rate & & & & $0.5 \mathrm{kN} / \mathrm{s}$ & & \\
\hline Unloading rate & $0.5 \mathrm{kN} / \mathrm{s}$ & $1.0 \mathrm{kN} / \mathrm{s}$ & $1.5 \mathrm{kN} / \mathrm{s}$ & $2.0 \mathrm{kN} / \mathrm{s}$ & $3.0 \mathrm{kN} / \mathrm{s}$ & $4.0 \mathrm{kN} / \mathrm{s}$ \\
\hline Rock index & $1 \#, 2 \#, 3 \#, 4 \#, 5 \#$ & $\begin{array}{c}31 \#, 32 \#, 33 \#, \\
34 \#, 35 \#\end{array}$ & $\begin{array}{c}36 \#, 37 \#, 38 \#, \\
39 \#, 40 \#\end{array}$ & $41 \#, 42 \#, 43 \#, 44 \#, 45 \#$ & $46 \#, 47 \#, 48 \#, 49 \#, 50 \#$ & $51 \#, 52 \#, 53 \#, 54 \#, 55 \#$ \\
\hline
\end{tabular}

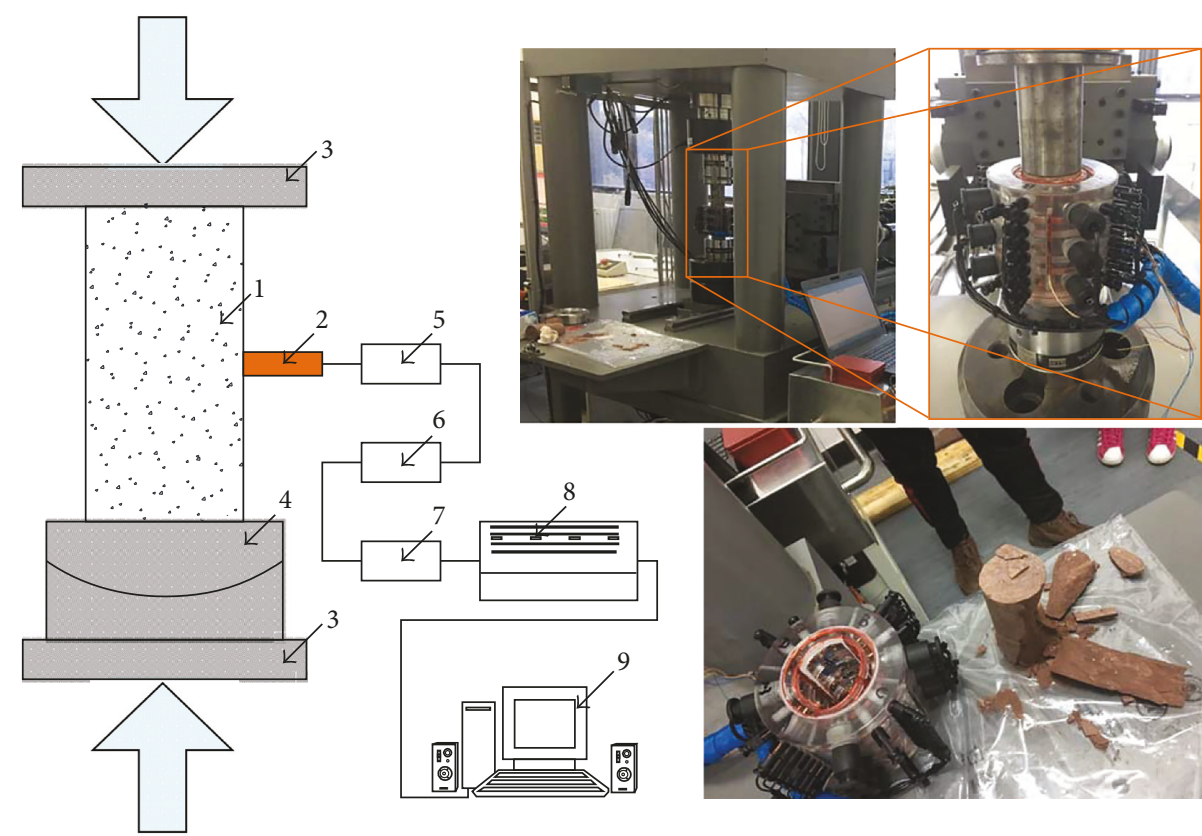

FIGURE 1: Schematic diagram of the AE measurement. 1: rock specimen; 2: AE sensor; 3: loading platens of the testing machine; 4: spherical adapter; 5: AE per-amplifiers; 6: filters of AE signals; 7: analog-to-digital converter; 8: signal acquisition unit; 9: data analyzer. (a) Combined experimental platform; (b) postfracturing rock specimen.

adopted until complete buckling failure of red sandstone specimens.

The experimental schematic diagram is shown in Figure 1. During the experiment, uniaxial cyclic compression of red sandstone specimens was accomplished by the MTS816 rock mechanics testing system (Figure 1(a)). This system is composed of loading part, testing part, and controlling part, which can realize several control modes, such as axial force or stress control, axial travel or stroke control, axial displacement or strain control, circumferential displacement or strain control, and so on. It meets requirements of multiple experiment designs. Servo-valve sensitivity of the system, maximum data collection frequency, and strain-loading rate were $290 \mathrm{~Hz}, 4000 \mathrm{~Hz}$, and $10^{-7} \sim 10^{-2} / \mathrm{s}$, respectively. The realtime monitoring of rock $\mathrm{AE}$ characteristics and changes of natural electric field during deformation and failure of red sandstone specimens was implemented by the SEMOS V1.0 seismic-electric-magnetic coupling effects observation system (Figure 1(b)) developed independently by the State Key Laboratory for Geomechanics and Deep Underground Engineering, China University of Mining and Technology. This system is mainly applied for synchronous observation of realtime signals of AE, self-potential, and electromagnetic radiation throughout the deformation and failure process of standard rock specimens under uniaxial compression or hydrofracture conditions, which is convenient for analysis of evolutionary characteristics of seismic wave field, electric field, and magnetic field in rock specimens. It can collect signals of 12 AE channels, 32 electric channels, and 6 transient electromagnetic channels simultaneously. This system has high sampling accuracy, 1.25 MHz real-time sampling frequency, $50 \mathrm{kHz}$ maximum response frequency, 24 bit $\mathrm{A} / \mathrm{D}$ conversion, dynamic range $\geq 258 \mathrm{~dB}$, and $10^{\circ} \sim 10^{6}$ time-varying gain. Limited by the experimental purpose, only one AE channel was used in these 


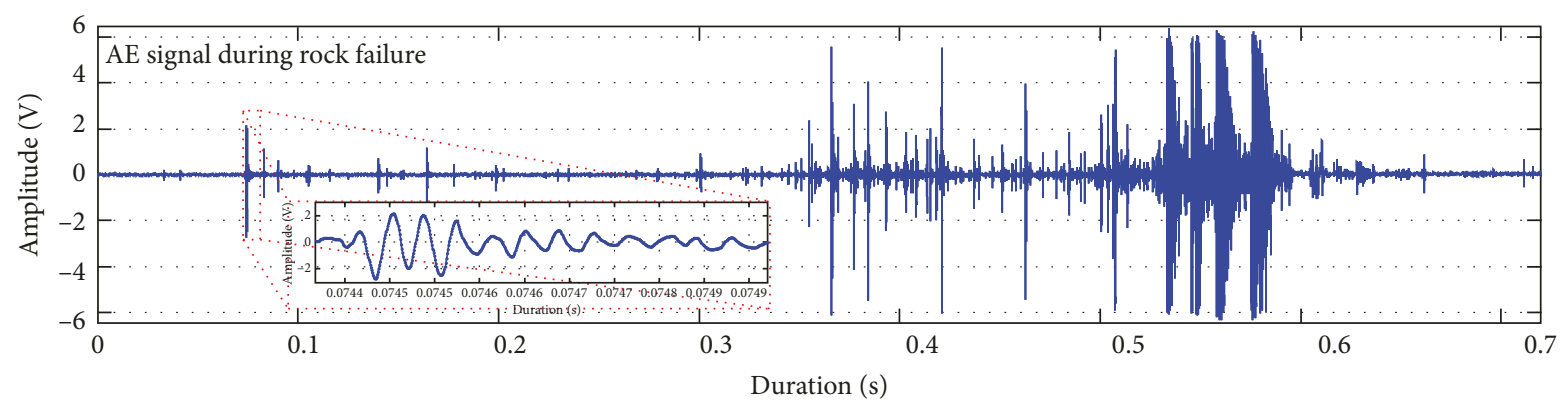

(a)

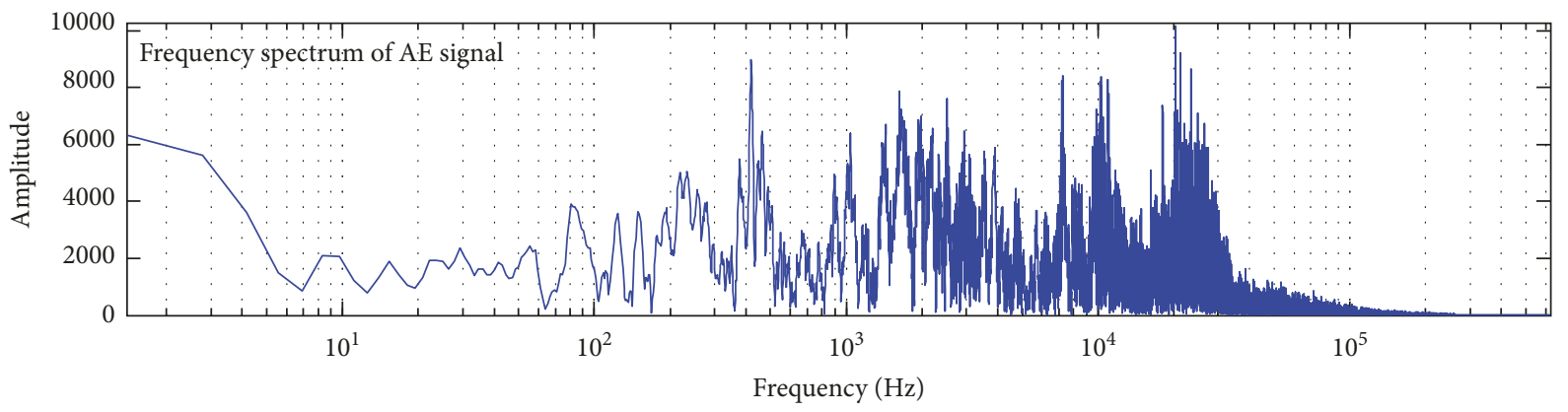

(b)

Figure 2: The AE signal and frequency spectrum of $1 \#$ red sandstone specimen at the complete fracturing moment. (a) Time-varying AE signal; (b) signal frequency spectrum.

tests. Above two systems were operated synchronously in the entire deformation and failure process of rock specimens.

\section{Testing Results of Rock AE Characteristics}

3.1. AE Signal at Rock Buckling Failure. Since the sampling frequency of the SEMOS V1.0 system is high, it results in the big data size of AE signals. Hence, only one section of signals at the buckling failure stage of a rock specimen was cut and exhibited, which is shown in Figure 2. A filter was set in the systemmonitoring process to inhibit background noises, thus enabling to gain high-purity AE signals. Seen from Figure 2 that as time goes on, $\mathrm{AE}$ phenomena in rock specimens intensify increasingly as approaching to complete buckling failure, manifested by growth of event density and ringing number. The most $\mathrm{AE}$ events are released at complete buckling failure of rock specimens and the corresponding energy is the largest. According to AE signals, rock specimens experience four expansions of principal cracks at the complete buckling failure, and the third expansion of principal cracks is the most violent one. Duration for development and connection of principal cracks is about $58.6 \mathrm{~ms}$ and the duration of the precursory fracture before the complete fracture is $194.2 \mathrm{~ms}$. AE signals of rocks during the buckling failure stage have wide frequency band which mainly concentrates in $1 \mathrm{kHz} \sim 35 \mathrm{kHz}$. It contains rich frequency components and the dominant frequency is $20.3 \mathrm{kHz}$.

3.2. Changes of AE Rings throughout the Compression Deformation and Failure of Rock Specimens. The relation curves between AE rings of red sandstone specimens and load in the cyclic loading-unloading process are shown in Figure 3.

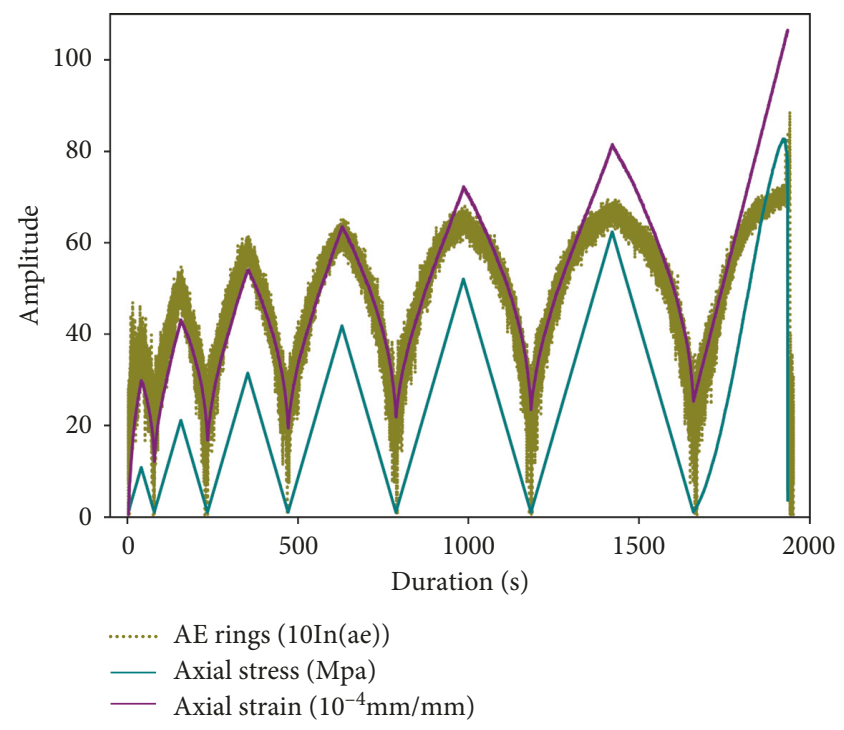

FIGURE 3: Relationships among the AE rings, axial stress, and strain of $1 \#$ red sandstone specimen under the uniaxial cyclic loading and unloading compression. Logarithmic format was applied to the $\mathrm{AE}$ counts and the axial strain was magnified $1 \times 10^{4}$ times.

Similar with uniaxial loading compression experiment, the deformation and failure process of rock specimens under uniaxial cyclic loading-unloading conditions is accompanied with abundant AE phenomena, and the energy of each $\mathrm{AE}$ event is extremely uneven. However, different from the uniaxial loading compression experiment, AE phenomena occur in both loading and unloading process and occur repeatedly with load changes. Rock specimens release 


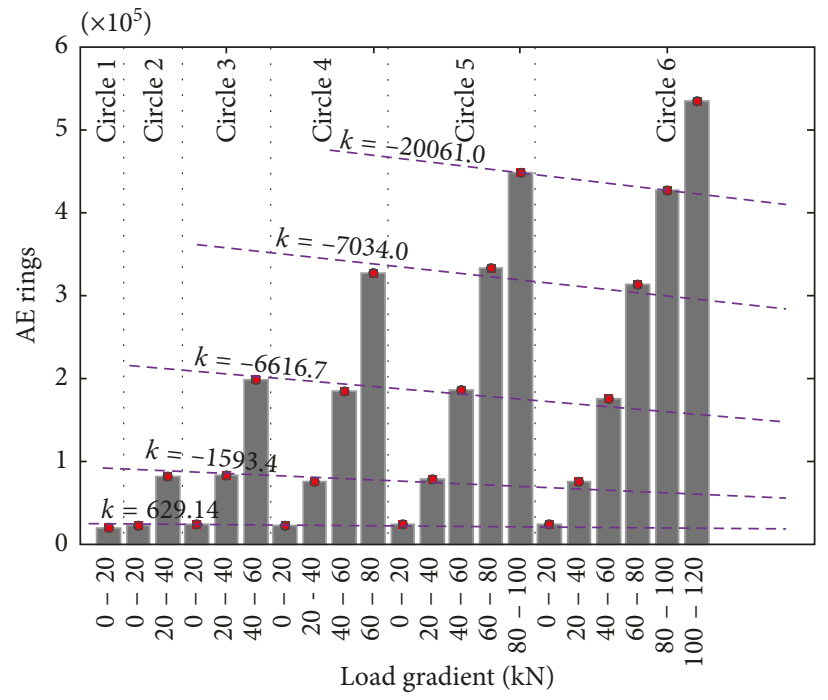

(a)

FIgUre 4: Changes of the AE rings with load gradients.

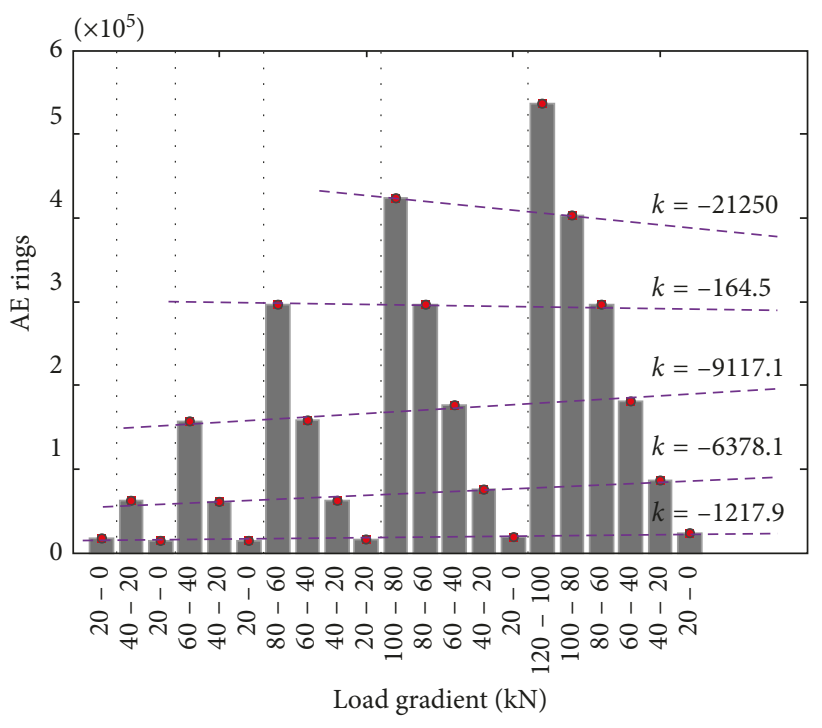

(b)

(a) Cyclic loading phases; (b) cyclic unloading phases.

different total AE rings in each loading-unloading cycle. The total $\mathrm{AE}$ rings increase gradually with the increase of current load level. In the loading-unloading cycle of $20 \mathrm{kN}$, the peak AE rings is 98 , and the total ringing number is $3.58 \times 10^{4}$. In the loading-unloading cycle of $120 \mathrm{kN}$, the peak AE rings is $9.97 \times 10^{2}$, and the total ringing number is $3.07 \times 10^{6}$. Load in the loading-unloading cycle of $120 \mathrm{kN}$ increases by only 6 times compared to that in the loading-unloading cycle of $20 \mathrm{kN}$, but peak AE rings and total ringing number increase by 10.2 times and 85.7 times, respectively. After reaching the compressive strength, rock specimens suffer instantaneous complete plastic buckling failure. At this moment, $\mathrm{AE}$ phenomena are the most violent, and the magnitude of $\mathrm{AE}$ rings also reaches the maximum $\left(6.73 \times 10^{3}\right)$. Moreover, $\mathrm{AE}$ rings decrease with the reduction of load. In the loadingunloading cycle of $100 \mathrm{kN}$, AE quantities decrease from $8.99 \times 10^{2}$ slowly to $1.27 \times 10^{2}$ when the load decreases from $100 \mathrm{kN}$ to $40 \mathrm{kN}$. In the loading-unloading cycle of $60 \mathrm{kN}$, AE rings decrease from the peak $4.51 \times 10^{2}$ to the valley 20 when the load decreases to 0 . The rock AE phenomena present a "saddle-shaped" variation law in the uniaxial cyclic loading-unloading process. Maximum and minimum of $\mathrm{AE}$ rings are well corresponding to load peak and valley.

According to variations of AE rings with stress gradient (Figure 4), in the same loading-unloading cycle, AE rings in the loading process are basically equivalent to AE rings in the unloading process. Variation of AE rings is highly symmetric centering at the peak load. Under cyclic equal loading, AE rings decrease with the increase of fatigue damages, but present an exponential growth with the linear growth of loads. The exponential growth of $\mathrm{AE}$ rings with the linear growth of stress load could be simplified (Figure 5).

Take the first $\left(\right.$ peak load $\left.=p_{1}\right)$ and second $\left(\right.$ peak load $\left.=p_{2}\right)$ loading cycles in the uniaxial cyclic loading-unloading process for example. When loads increases from $p_{0}$ to $p_{1}$, the rock specimens experience the first uniaxial loading compression

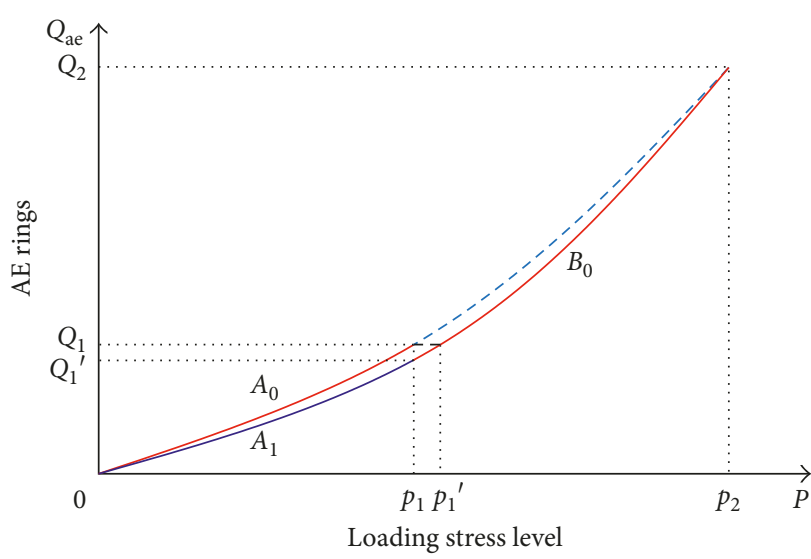

Figure 5: Simplified increasing model of the rock AE rings.

(section $A_{0}$ ). When load increases from $p_{0}$ to $p_{2}$ again after the unloading, this loading process can be divided into two sections: section $p_{0}-p_{1}$ (section $A_{1}$ ) which coincides with the first cycle and the primary $20 \mathrm{kN} \sim 40 \mathrm{kN}$ section (section $B_{0}$ ). In section $A_{1}$, load increases from $p_{0}$ to $p_{1}$, which coincides with load changes in section $A_{0}$. Nevertheless, AE rings decrease with the increase of fatigue damages. Therefore, AE quantities of section $A_{1}\left(Q_{1}^{\prime}\right)$ is smaller than the $\mathrm{AE}$ quantities of section $A_{0}\left(Q_{1}\right)$. In section $B_{0}$, the load increases from $p_{1}$ to $p_{2}$, which rock specimens experience for the first time. Further development and expansion of internal cracks are unique under $p_{1}-p_{2}$, and the produced AE phenomena are unrepeatable. In this period, $\mathrm{AE}$ rings still maintain an exponential growth, and the growth rate $(\gamma b)$ is significantly larger than the $\mathrm{AE}$ growth rate $(\gamma a)$ in section $A_{0}$. In this way, this makes up disadvantages that $\mathrm{AE}$ quantities in section $A_{1}$ are smaller than that in section $A_{0}$ on one hand. On the other hand, this maintains an overall growth trend of AE quantities. Under cyclic equivalent loading, AE rings change differently. 


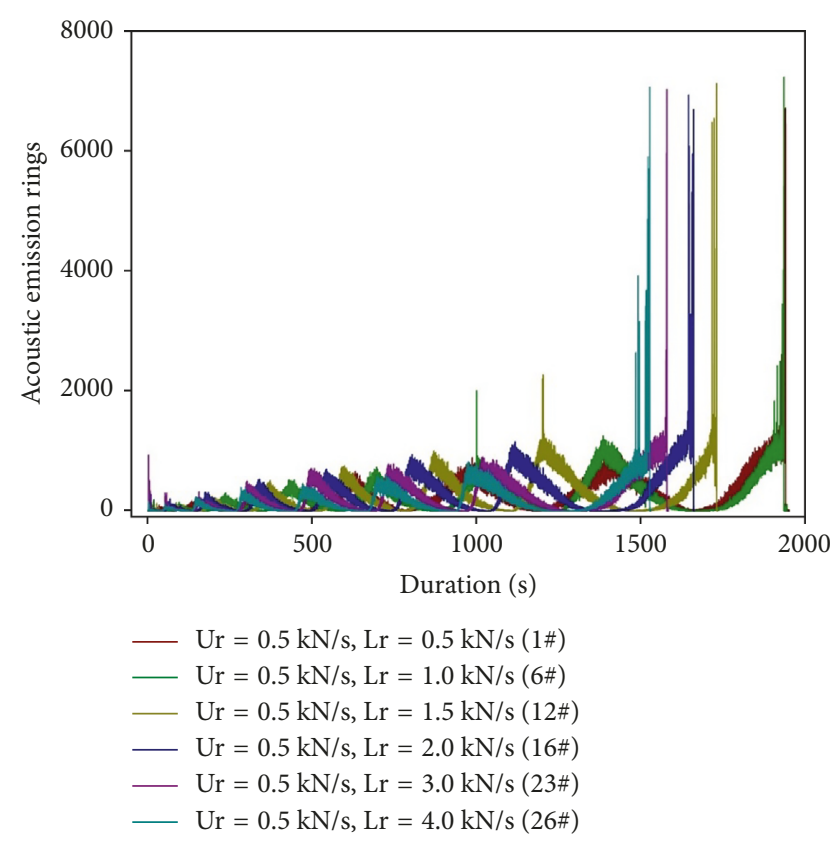

FIgURE 6: Changes of rock $\mathrm{AE}$ rings with the monitoring time under the uniaxial cyclic loading and unloading compression $(\mathrm{Ur}=0.5 \mathrm{kN} / \mathrm{s} ; \mathrm{Lr}=0.5 \mathrm{kN} / \mathrm{s} \sim 4.0 \mathrm{kN} / \mathrm{s})$.

AE rings are positively correlated with fatigue damages when the cyclic unloading load is low but is negatively correlated with fatigue damages when the cyclic unloading load is high.

Changes of rock $\mathrm{AE}$ phenomena reveal that under uniaxial cyclic loading-unloading conditions, the development degree of internal small cracks in rock specimens is far higher than that under uniaxial compression conditions. AE phenomena occur during the strain deformation of rock specimens. In the initial stage of external loading, the original cracks in rock specimens become more and more dense gradually and AE activities are weak, accompanied with continuous release of weak elastic waves. With the gradual increase of applied load, rock damages intensify continuously, which facilitates compaction and extension of internal original cracks of rocks as well as connection of abundant induced cracks, thus resulting in more and more active AE phenomena. AE rings concentrate gradually and big AE events increase significantly. From the macroscopic perspective, AE rings increase with the load. However, AE rings fluctuate to some extent in a short-time domain when viewed from the microscopic perspective.

\section{Impact of Loading Rates and Unloading Rates on the AE Characteristics of Rock Specimens}

4.1. Impact of Loading Rates on Rock AE Characteristics. To explore influences of loading rate on AE characteristics of red sandstone specimens, rock $\mathrm{AE}$ phenomena in the compression deformation and failure process of uniaxial loading-unloading cycles under different loading rates but fixed unloading rate $(\mathrm{Ur}=0.5 \mathrm{kN} / \mathrm{s})$ were compared. Experimental results are shown in Figures 6 and 7 .
Given fixed unloading rate, compression deformation of rock specimens accelerates with the gradual increase of loading rate, thus shortening the process from initial deformation to complete failure. AE rings increase sharply at the rock failure after reaching the peak intensity. AE quantities released by rock specimens at the rock failure under six loading rates are basically equivalent. Throughout the uniaxial cyclic loading-unloading compression deformation and failure process, the total AE rings released by rock specimens decrease gradually with the increase of loading rate (Figure $7(\mathrm{a})$ ). The total AE counts released by $1 \#$ rock specimen throughout the deformation and failure process is $9.89 \times 10^{6}$, but that by 26 \# rock specimen decreases to $5.39 \times 10^{6}$. In contrast, total $\mathrm{AE}$ counts decrease by 0.46 times when the loading rate increases by 7 times. The total $\mathrm{AE}$ counts of rock specimens and loading rate have an approximate negative linear correlation. The slope of the fitting straight is $-1.19 \times 10^{6}$.

In Figure $7(\mathrm{~b})$, under single loading-unloading combination, AE rings in the single cycle increase continuously in the loading process, but $\mathrm{AE}$ rings show different variation trends in the uniaxial compression stage after the cyclic loading. When the loading rate is $\mathrm{Lr}=0.5 \mathrm{kN} / \mathrm{s}, 1.0 \mathrm{kN} / \mathrm{s}$, and $1.5 \mathrm{kN} / \mathrm{s}$, total AE counts decline significantly compared to those in the previous cycle. When $\mathrm{Lr}=2.0 \mathrm{kN} / \mathrm{s}, 3.0 \mathrm{kN} / \mathrm{s}$, and $4.0 \mathrm{kN} / \mathrm{s}$, the total AE counts increase continuously, which are higher than those in the previous cycle. This is closely related with underdeveloped internal microcracks of rocks which are caused by high loading rate. Under high loading rate, internal microcracks in the early elastic-plastic compression deformation stage of rock specimens are underdeveloped, and AE quantities increase continuously in the late compression failure stage. Meanwhile, the loading rate is closely related with the growth rate of AE rings. Given fixed loading rate, the growth rate of AE rings is constant. Under the equal load level, both maximum AE quantities and total AE counts released by rock specimens in the single loading-unloading cycle decrease level by level when the loading rate increases continuously. For instance, in the loading-unloading cycle of $120 \mathrm{kN}$, the maximum AE quantities decrease from 1044 to 614 and the total AE counts decrease from $3.07 \times 10^{6}$ to $9.13 \times 10^{5}$ when the loading rate increases from $0.5 \mathrm{kN} / \mathrm{s}$ to $4.0 \mathrm{kN} / \mathrm{s}$. Although the loading rate increases by as high as $700 \%$, the maximum $\mathrm{AE}$ quantities and total $\mathrm{AE}$ counts decrease by only $41.2 \%$ and $70.3 \%$, respectively.

In Figures 7(c) and 7(d), in the single loading-unloading cycle under the equal load level, total AE counts released by rock specimens in the loading process and unloading process decrease gradually with the gradual growth of loading rate. In contrast, total $\mathrm{AE}$ counts in the loading process reduce more significantly, showing approximate multiple reductions. However, AE phenomena in the unloading process are influenced slightly. The total AE counts in the unloading process exceed the total AE counts in the loading process gradually. In the uniaxial compression stage after cyclic loading, the total AE counts in the loading process increase continuously. Moreover, the higher the loading rate, the higher the growth rate of total $\mathrm{AE}$ counts and the 


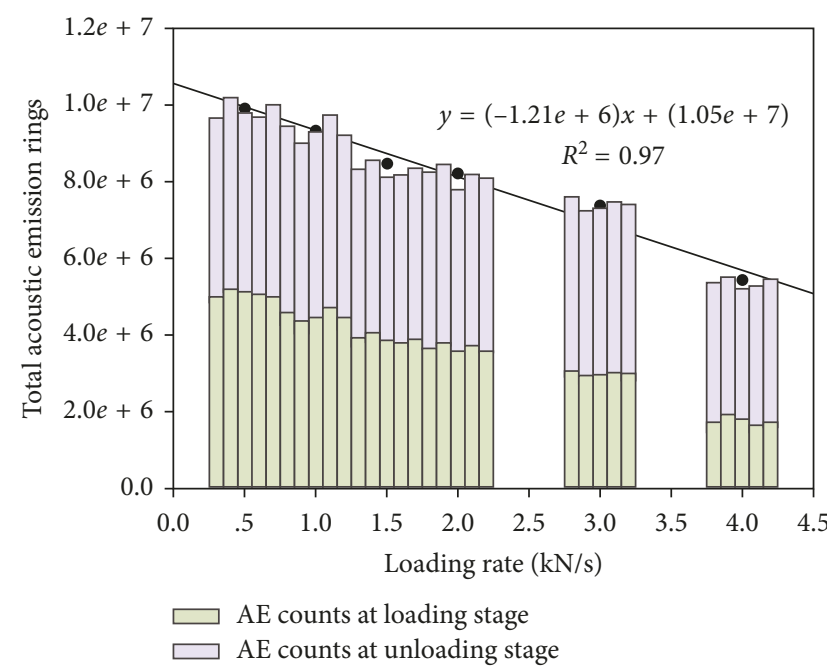

(a)

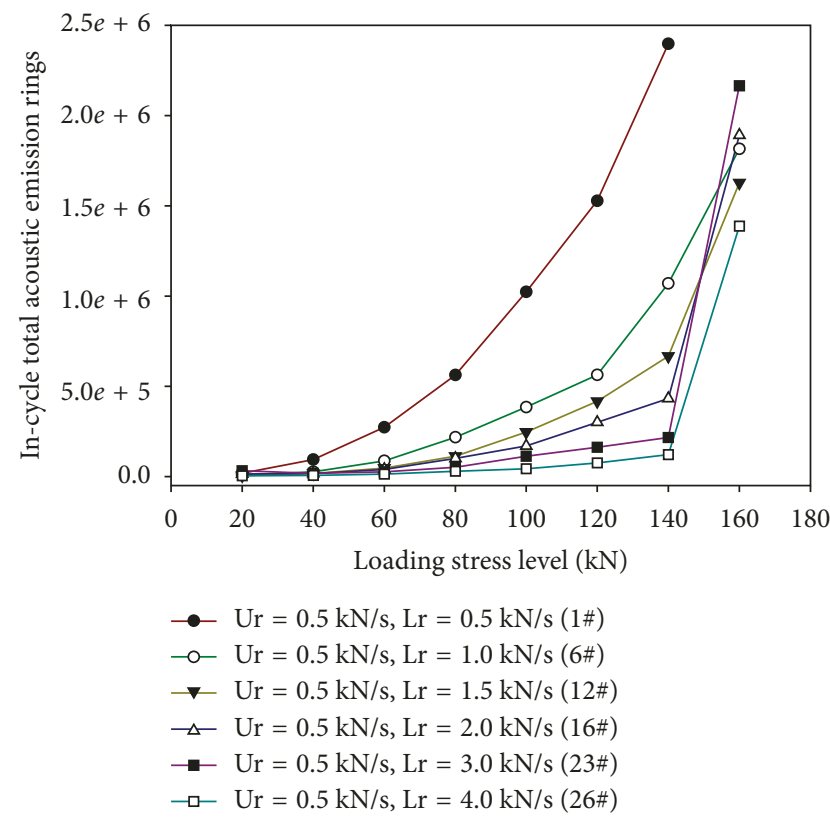

(c)

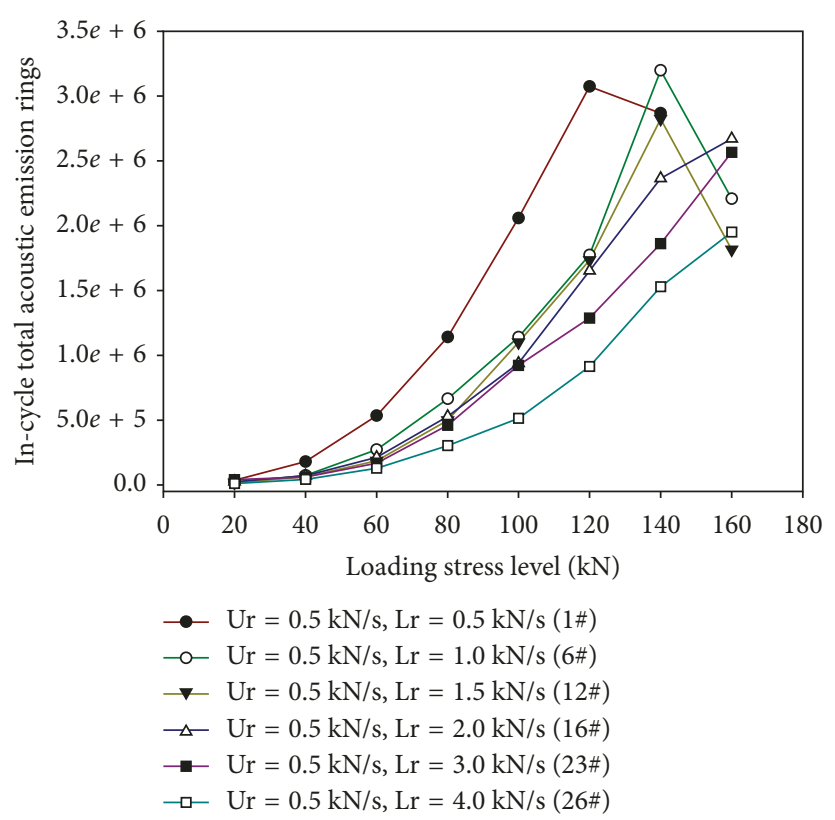

(b)

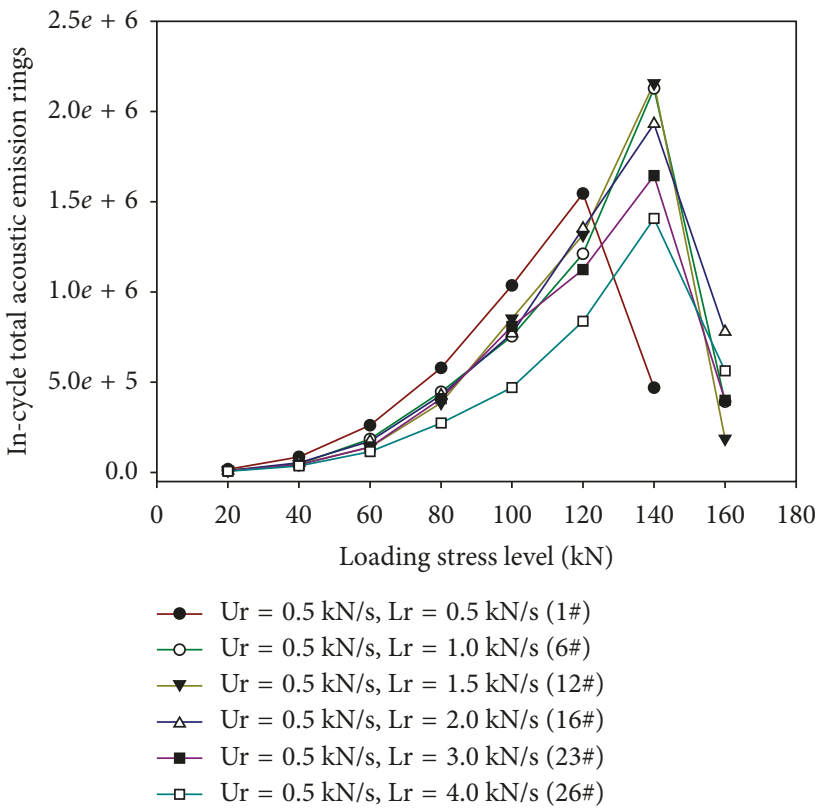

(d)

Figure 7: Variation of the AE characteristics of red sandstone specimens ( $\mathrm{Ur}=0.5 \mathrm{kN} / \mathrm{s} ; \mathrm{Lr}=0.5 \mathrm{kN} / \mathrm{s} \sim 4.0 \mathrm{kN} / \mathrm{s}$ ). (a) Total AE rings versus loading rates; (b) total AE rings of each cycle versus loading stress levels; (c) total AE rings at the loading stage of each cycle versus loading stress levels; (d) total AE rings at the unloading stage of each cycle versus loading stress levels.

higher the proportion of total AE counts during the loading process of the loading-unloading cycles. In the unloading process after compression failure, although there are highintensity $\mathrm{AE}$ phenomena, the total $\mathrm{AE}$ counts reduce significantly compared to those in the unloading process of the previous cycle.

Results demonstrate that the loading rate will influence rock $\mathrm{AE}$ characteristics in the compression deformation and failure stage significantly. The compression deformation of rock specimens prolongs under low loading rate. Abundant physical mechanical behaviors (e.g., initiation, formation, connection, and extension of induced microcracks) are developed completely in rock specimens, manifested by high-quantity and high-density strong $\mathrm{AE}$ phenomena. Different from AE phenomena, when the loading rate ranges between $1.0 \mathrm{kN} / \mathrm{s}$ and $4.0 \mathrm{kN} / \mathrm{s}, \mathrm{AE}$ phenomena of rock specimens in the compression deformation process of uniaxial loading-unloading cycles, when $\mathrm{Lr}=0.5 \mathrm{kN} / \mathrm{s}$, are all stronger than AE phenomena under other loading rate, and they reach the compressive strength $(82.2 \mathrm{MPa})$ before 


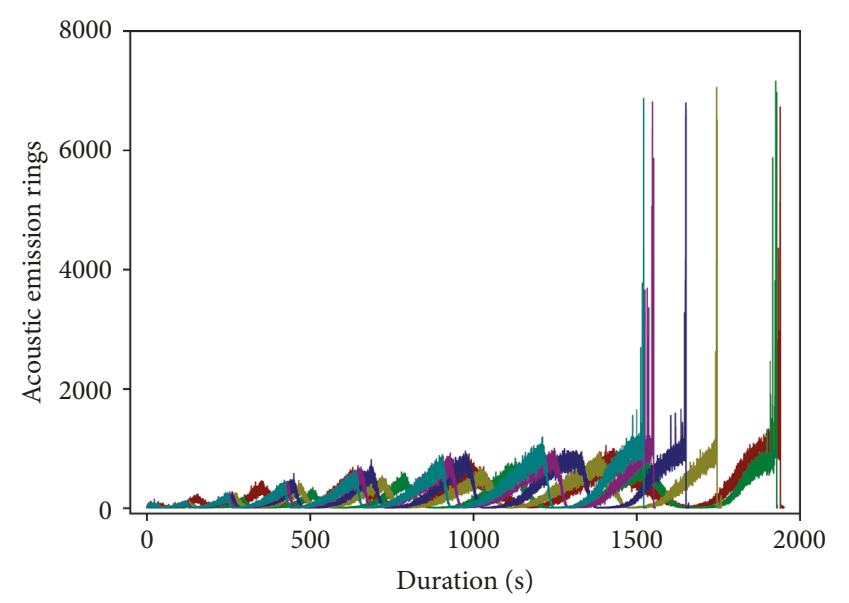

$\mathrm{Lr}=0.5 \mathrm{kN} / \mathrm{s}, \mathrm{Ur}=0.5 \mathrm{kN} / \mathrm{s}(1 \#)$
$\mathrm{Lr}=0.5 \mathrm{kN} / \mathrm{s}, \mathrm{Ur}=1.0 \mathrm{kN} / \mathrm{s}(33 \#)$
$\mathrm{Lr}=0.5 \mathrm{kN} / \mathrm{s}, \mathrm{Ur}=1.5 \mathrm{kN} / \mathrm{s} \mathrm{(38 \# )}$
$\mathrm{Lr}=0.5 \mathrm{kN} / \mathrm{s}, \mathrm{Ur}=2.0 \mathrm{kN} / \mathrm{s}(41 \#)$
$\mathrm{Lr}=0.5 \mathrm{kN} / \mathrm{s}, \mathrm{Ur}=3.0 \mathrm{kN} / \mathrm{s}(47 \#)$
$\mathrm{Lr}=0.5 \mathrm{kN} / \mathrm{s}, \mathrm{Ur}=4.0 \mathrm{kN} / \mathrm{s}(52 \#)$

FIgURe 8: Changes of rock $\mathrm{AE}$ rings with the monitoring time under the uniaxial cyclic loading and unloading compression $(\mathrm{Lr}=0.5 \mathrm{kN} / \mathrm{s}, \mathrm{Ur}=0.5 \mathrm{kN} / \mathrm{s} \sim 4.0 \mathrm{kN} / \mathrm{s})$.

$140 \mathrm{kN}$. This reflects that under low loading rate, complete crack development reduces the compressive strength of rocks, thus causing complete plastic buckling failure of rocks under low load.

When the loading rate increases gradually, compression deformation of rock specimens accelerates significantly, which shortens the loading process gradually. Even in multiple loading-unloading cycles, the abundant microcracks in rock specimens are difficult to be developed completely in a short period. Extension of relatively large induced cracks is the main deformation and failure of rock specimens, which is manifested by some enhancing $\mathrm{AE}$ signals and weakening overall $\mathrm{AE}$ phenomena in the compression deformation and failure of rocks. Total $\mathrm{AE}$ rings reduce obviously. Particularly, since microcracks in rocks could not develop completely when the loading rate exceeds $2.0 \mathrm{kN} / \mathrm{s}$, considerable energy absorbed by rocks could not be consumed timely and effectively by physical and mechanical behaviors like crack extension, increasing possibility of brittle fracture of rocks in the final compression failure stage when load exceeds the compressive strength [24]. High loading rate will bring quicker extension and larger size of principal cracks in rocks and more $\mathrm{AE}$ counts are released instantly as well as in higher energy quantity. Brittle failure of rocks intensifies with the gradual increase of loading rate.

4.2. Impact of Unloading Rates on Rock AE Characteristics. Similarly, to explore influences of unloading rate on $\mathrm{AE}$ characteristics of red sandstone specimens, rock AE phenomena in the compression deformation and failure process of uniaxial loading-unloading cycles under different unloading rates but fixed loading rate $(\mathrm{Lr}=0.5 \mathrm{kN} / \mathrm{s})$ were compared. Experimental results are shown in Figures 8 and 9.

Given fixed loading rate, total AE counts released by rock specimens in the compression deformation and failure process of uniaxial loading-unloading cycles change irregularly with the gradual increase of loading rate (Figure 9(a)). Generally, under the combination of low loading rate and low unloading rate $(\mathrm{Lr}=0.5 \mathrm{kN} / \mathrm{s}$ and $\mathrm{Ur}=0.5 \mathrm{kN} / \mathrm{s})$, except the significantly higher total $\mathrm{AE}$ counts during the compression deformation process, the total $\mathrm{AE}$ counts under different unloading rates are similar, which decrease gradually on the whole. This reflects that unloading rate influences $\mathrm{AE}$ phenomena in the compression deformation process of rocks slightly. The difference of total AE counts is mainly caused by anisotropism of rock specimens.

For each loading-unloading cycle, the total AE rings increase gradually with the increase of cyclic load level (Figure 9(b)). The growth curves of total AE rings in the single cycle almost overlap as the unloading rate increases $(\mathrm{Ur}=1.0 \sim 4.0 \mathrm{kN} / \mathrm{s}$ ), showing no distinct difference on the whole. The growth curves of total AE rings in the uniaxial compression stage after the cycle decline gradually. However, the total $\mathrm{AE}$ counts in the single cycle increase continuously when $\mathrm{Ur}=4.0 \mathrm{kN} / \mathrm{s}$, indicating that under high unloading rate, internal cracks are underdeveloped in early stages and continue to develop in the final compression deformation stage. AE phenomena intensifie continuously. Both total $\mathrm{AE}$ rings at the loading stage of each cycle and total $\mathrm{AE}$ rings at the unloading stage of each cycle increase when the load level increases gradually (Figure 9(c)). The total $\mathrm{AE}$ counts in the unloading process increase more obviously. The total AE counts in the loading process is not influenced by the unloading rate. It remains basically same with the gradual increase of unloading rate. The difference of $\mathrm{AE}$ counts is mainly attributed to anisotropism of rock specimens. When $\mathrm{Ur}=1.5 \mathrm{kN} / \mathrm{s}, 2.0 \mathrm{kN} / \mathrm{s}$, and $3.0 \mathrm{kN} / \mathrm{s}$, total $\mathrm{AE}$ counts decrease to some extent compared to those of the previous cycle. This is because rock specimens reach the UCS and make buckling failures quickly in the final compression deformation stage, releasing fewer $\mathrm{AE}$ rings in this short period.

Total AE rings at the unloading stage of each cycle were affected dramatically by unloading rates (Figure 9(d)). The total AE counts decrease gradually with the increase of unloading rate. AE phenomena in the unloading process are very strong when the loading rate and unloading rate are equal $(\mathrm{Lr}=0.5 \mathrm{kN} / \mathrm{s}$ and $\mathrm{Ur}=0.5 \mathrm{kN} / \mathrm{s})$, but weaken significantly when the unloading rate is larger than the loading rate. Total $\mathrm{AE}$ counts in the same cycle decrease gradually with the increase of Ur/Lr. Meanwhile, the total AE counts are positively correlated with the load peak. In the final failure stage, $\mathrm{AE}$ quantities decrease when $\mathrm{Ur}=0.5 \mathrm{kN} / \mathrm{s} \sim 2.0 \mathrm{kN} / \mathrm{s}$ and increase continuously when $\mathrm{Ur}=3.0 \mathrm{kN} / \mathrm{s} \sim 4.0 \mathrm{kN} / \mathrm{s}$, indicating that high unloading rate is conducive to accelerate recovery of rock deformation and residual strain. Therefore, internal microcracks become more and more underdeveloped, thus reducing the intensity of $\mathrm{AE}$ phenomena and quantities. In other words, the higher the unloading rate, the fewer the $\mathrm{AE}$ rings in the unloading process. 


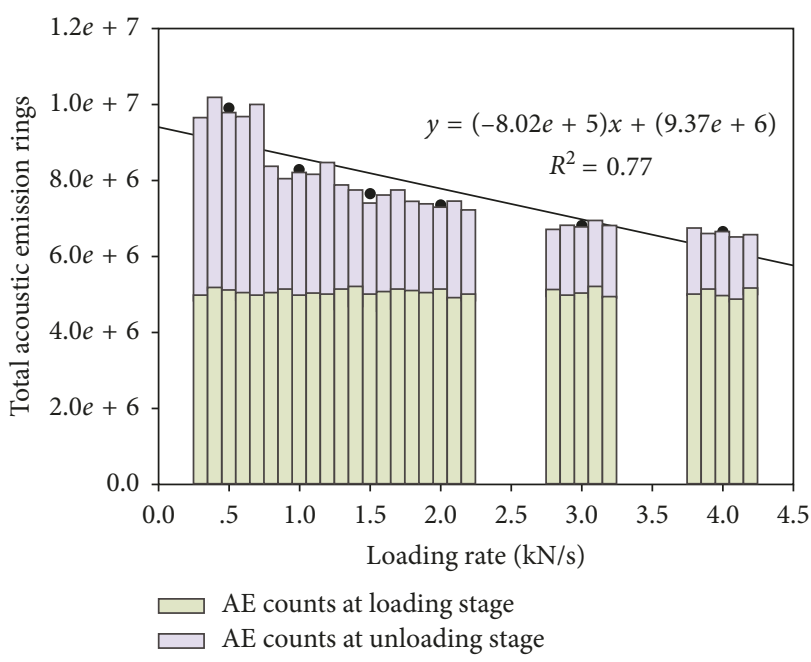

(a)

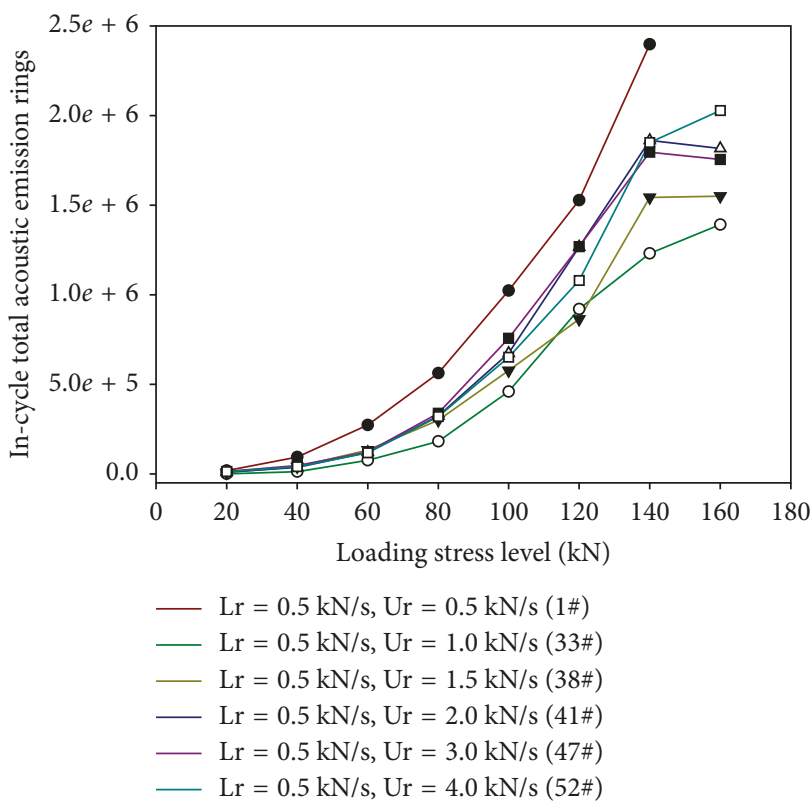

(c)

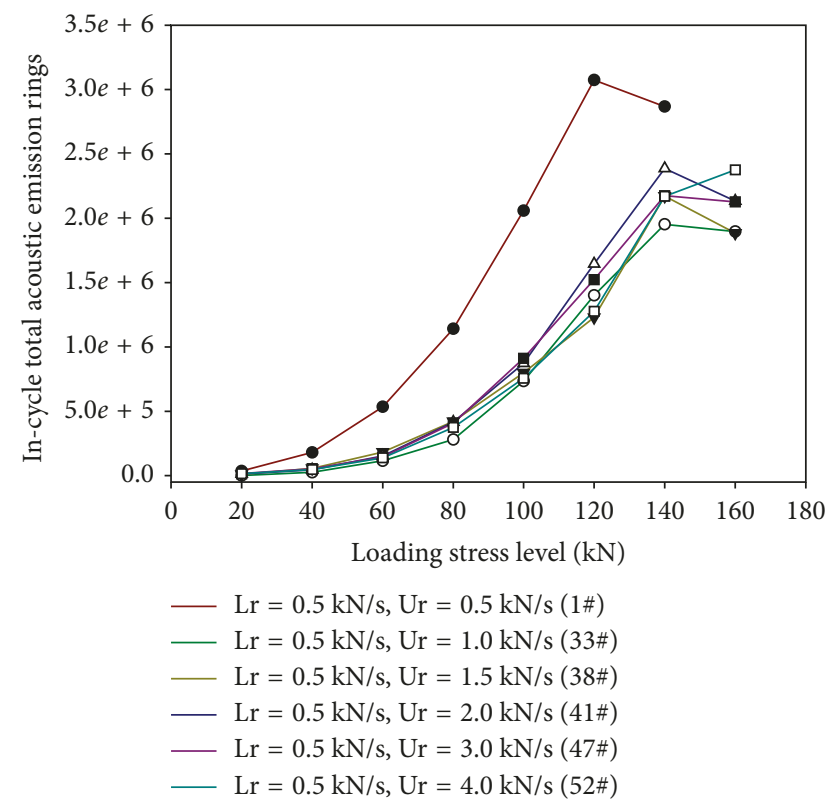

(b)

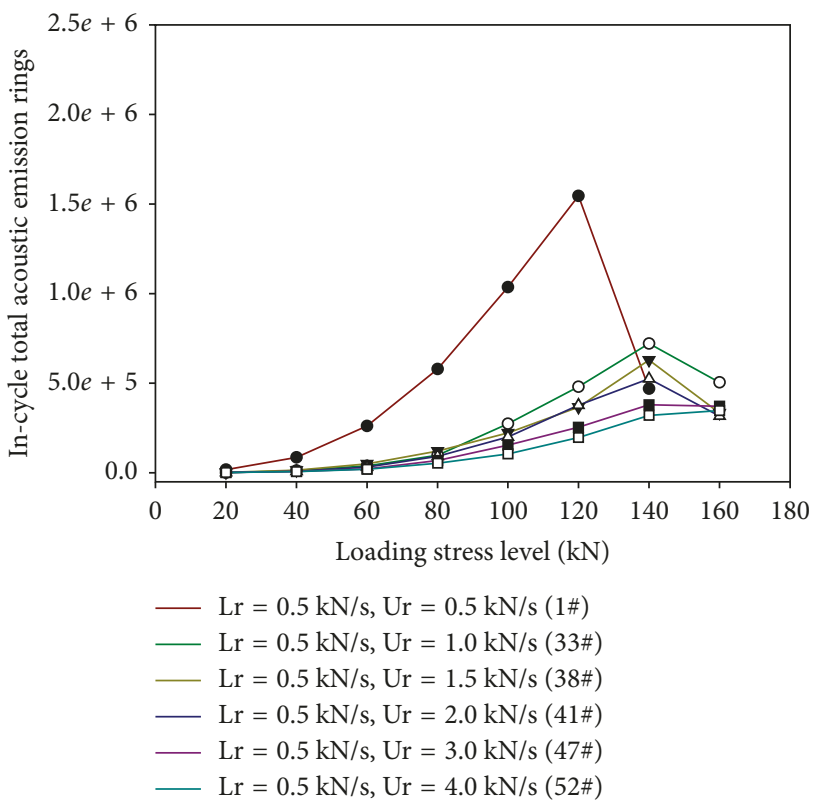

(d)

Figure 9: Variation of the AE characteristics of red sandstone specimens $(\mathrm{Lr}=0.5 \mathrm{kN} / \mathrm{s}, \mathrm{Ur}=0.5 \mathrm{kN} / \mathrm{s} \sim 4.0 \mathrm{kN} / \mathrm{s})$. (a) Total AE rings versus loading rates; (b) total AE rings of each cycle versus loading stress levels; (c) total AE rings at the loading stage of each cycle versus loading stress levels; (d) total AE rings at the unloading stage of each cycle versus loading stress levels.

Elastoplastic deformation of internal microstructure of rocks occurs under the influence of external loads. The unloading process of rock specimens is a recovery process of strain deformation. In the elastic deformation stage, elastic strain of rocks recovers better, but cracks develop slightly and AE phenomena are not apparent. Nevertheless, plastic deformation of rocks intensifies gradually with the increase of external loads. When the compacted rock skeleton structure (the solid phase except gas phase and liquid phase here) makes strain recovery in the unloading stage, the internal elastic microstructure deformation recovers quickly, whereas the plastic microstructure (crack) deformation is almost irreversible. The resilience of the elastic skeleton structure drives tip extension and further expansion of plastic compaction cracks as well as intensifies development and connection of new cracks for fracture development. These will induce and strengthen AE phenomena to some extent. After rock specimens enter into the plastic-yielding stage, the continuous load increase aggravates rock damages, resulting in continuous growth of AE rings and increasing occurrence frequency of strong $\mathrm{AE}$ events. As the unloading rate increases 
gradually, the strain recovery period of rock specimens shortens. In the limited time, elastic microstructure mainly drives development and expansion of dominant cracks, but microcracks of delayed development are not represented completely when the rock specimens have entered into the next loading process, thus reducing $\mathrm{AE}$ counts and weakening $\mathrm{AE}$ phenomena gradually with the increase of unloading rate. The energy released by a single $\mathrm{AE}$ event will enhance to some extent.

Microcracks development in rock specimens is a process of continuous closing, regeneration, extension, and connection. Speed and intensity of rock damages are closely related with frequency and intensity of $\mathrm{AE}$ events. $\mathrm{AE}$ phenomena occur in both the loading process and unloading process of rock specimens as long as loads change the rock strain. The loading rate and unloading rate can influence $\mathrm{AE}$ phenomena directly to some extent. Given fixed external loading-unloading cycles, rock AE phenomena under different loading and unloading rates differ significantly. Increasing loading and unloading rates will accelerate deformation and failure process of rocks and shorten the cyclic rupture period, thus changing the total $\mathrm{AE}$ counts. The total $\mathrm{AE}$ counts of rock specimen decrease with the increase of loading rate, but keep basically same with the increase of unloading rate, indicating that loading process influences rock damages more seriously and directly. Loading process is the active period of $\mathrm{AE}$ phenomena.

\section{Discussion on Felicity Effect of Rock AE Phenomena in Uniaxial Cyclic Loading and Unloading Compressions}

Rock AE phenomena are unrepeatable under the influence of external loads. That is, one time of primary expansion of internal microcracks only induces one $\mathrm{AE}$ event with a certain amount of intensity. Therefore, quantity and intensity of AE phenomena basically represent the development degree and expansion intensity of internal microcracks in the rock body. Seen form the monitoring experiments of the $\mathrm{AE}$ phenomena of red sandstone specimens in the uniaxial cyclic loading-unloading compression conditions, different degrees of AE phenomena take place in any stage of the loading-unloading cycles, and the AE quantities are positively correlated with loads. The situation that $\mathrm{AE}$ phenomena weaken significantly and even disappear when the current stress level is lower than the previous maximum stress level is not observed. This reveals that rock $\mathrm{AE}$ phenomena under uniaxial cyclic loading have anti-Kaiser effect, that is, the Felicity effect [25-27]. Influenced by stress level and stress pathway, the Kaiser effect does not exist in all rocks. Therefore, the Felicity effect is introduced for better description of rock AE phenomena under the uniaxial cyclic loading-unloading conditions. The Felicity effect refers to $\mathrm{AE}$ events that begin to increase significantly when stress is smaller than previous maximum stress level in the cyclic loading process [28]. The Felicity effect is quantified by the Felicity ratio: the current stress/previous maximum stress level when $\mathrm{AE}$ events begin to increase significantly.

$$
\mathrm{Fr}_{i}=\frac{P_{\mathrm{ae}_{i}}}{P_{\max _{(i-1)}}},
$$

where $\mathrm{Fr}_{i}$ is the Felicity ratio of the $i$ th loading-unloading cycle, $P_{\mathrm{ae}_{i}}$ is the stress level when AE rings begin to increase significantly in the $i$ th loading-unloading cycle, and $P_{\max _{(i-1)}}$ is the maximum stress level in the $(i-1)$ th loading-unloading cycle. As a quantitative parameter, the Felicity ratio is a wider description to irreversibility of the AE process of materials and can reflect severity of original damages or structural defects in materials. It has become an important evaluation index of defect severity. Under general conditions, the Kaiser effect is true only when $\mathrm{Fr}_{i}>1$. $\mathrm{Fr}_{i}<1.0$ reflects serious material damages. The smaller the Felicity ratio, the more serious the original damages or structural defect of rock specimens. During the loading-unloading cycles, changes of the Felicity ratio can reflect evolutionary process of rock damages objectively.

In practical application, the key to gain value of the $\mathrm{Fe}$ licity ratio is to determine the stress level when $\mathrm{AE}$ rings begin to increase significantly in the cyclic loading process. However, there is no agreed standard to determine the start point of sharp increase of $\mathrm{AE}$ phenomena. According to the guideline of the AE Monitoring Committee of American Reinforced Plastics (CARP), AE rings exceed 20 when the load is higher than $10 \%$ [1]. Combining with the Felicity effect, the Felicity ratio is determined by the stress parameters, and the stress level is determined by $\mathrm{AE}$ rings. The sharp growth of $\mathrm{AE}$ phenomena is relative to $\mathrm{AE}$ rings at previous maximum stress. Therefore, the stress level when AE events begin to increase significantly could be determined by the ratio between $\mathrm{AE}$ rings in the $i$ th loading process $\left(\Delta Q_{i}\right)$ and $\mathrm{AE}$ rings at the maximum stress level in the $(i-1)$ th loading process $\left(\Delta Q_{i-1}{ }^{\max }\right)$. Once $\mathrm{AE}$ quantities exceed the $\mathrm{AE}$ counts at the maximum stress level, that is, when $\Delta Q_{i} / \Delta Q_{i-1}{ }^{\max } \geq 1$, it could be believed that $\mathrm{AE}$ events begin to increase significantly and the current stress level in the $i$ th loading process reaches the stress level when $\mathrm{AE}$ quantities begin to increase greatly. However, since AE phenomena fluctuate to some extent in the adjacent time domain and such fluctuation amplitude is larger under higher stress level, $\Delta Q_{i-1}{ }^{\max }$ and $\Delta Q_{i}$ are difficult to be determined. Therefore, the wavelet transform signal processing method is introduced in this paper. Variation of AE rings with time is viewed as a section of shifted signal which is decomposed into the principal skeleton of AE phenomena (Figure 10(a)) and detailed noise of $\mathrm{AE}$ phenomena (Figure 10(b)). Whether AE rings under current stress less increase significantly could be judged by the main features of $\mathrm{AE}$ phenomena. On this basis, the relation curve between the Felicity ratio of rock $\mathrm{AE}$ phenomena and cyclic loading loads is gained (Figure 11).

Under the combination of different loading rates and unloading rates, the Felicity ratio of rock AE phenomena has distinct variation law (Figure 11). It decreases gradually when cycles and loads increase continuously. Under the combination of same loading rate and unloading rate, the Felicity ratios of AE phenomena of different rock specimens differ greatly. However, such difference decreases gradually with the continuous growth of cycles and loads. The 


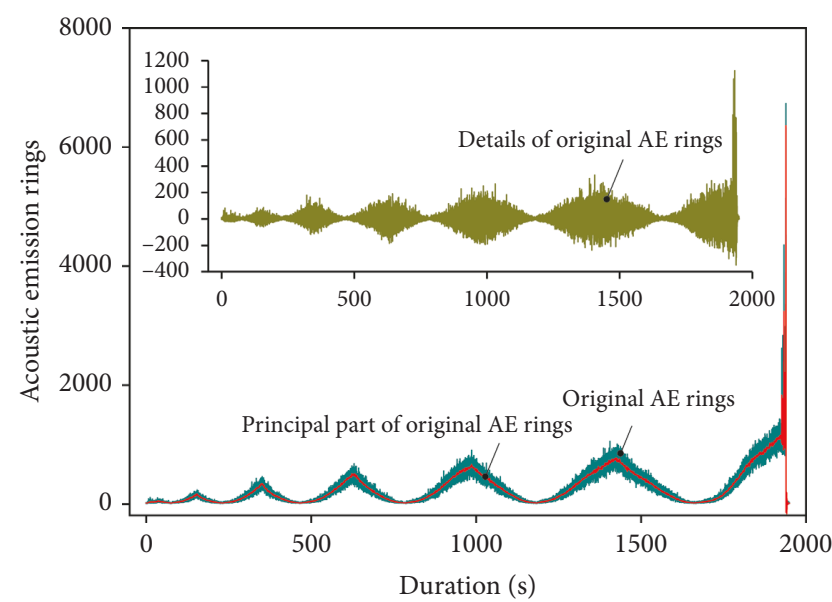

Figure 10: Time-varying AE rings during the entire rock deformation and failure.

variation range of the Felicity ratio is between 0.85 and 1.45. The variation law of Felicity ratio of rock materials is closely related with the growth pattern of $\mathrm{AE}$ rings in the loading process. Based on the multistage growth model of relationship between $\mathrm{AE}$ rings and loading gradient of rock specimens (Figure 5), AE quantities decrease slightly when the load increases to $p_{1}$ for the second time. To make $\mathrm{AE}$ quantities reach the level $Q_{1}$ at $A_{0}$, load shall be increased a little to $p_{1}{ }^{\prime}$. According to the definition of the Felicity effect, the Felicity ratio determined by this cycle is

$$
\mathrm{Fr}_{2}=\frac{p_{1}^{\prime}}{p_{1}}=\frac{p_{1}+\Delta p_{1}}{p_{1}}=1+\frac{\Delta p_{1}}{p_{1}}
$$

Obviously, the Felicity ratio is larger than 1, indicating that rock $\mathrm{AE}$ characteristics in the elastic compression deformation stage conform to the Kaiser effect. With the increase of loading-unloading cycles, the load peak of different cycles increases gradually. Higher loads will cause more intensifying and dense $\mathrm{AE}$ phenomena and more $\mathrm{AE}$ rings. In the cyclic loading process under high loads, the load growth to exceed the load peak of the previous cycle which is needed for $\mathrm{AE}$ quantities to reach $\mathrm{AE}$ quantities corresponding to the load peak of the previous cycle is not very big. Actually, $\Delta p$ decreases gradually. Therefore, the Felicity ratio is negatively correlated with loading-unloading cycles. The Felicity ratio approaches to 1 gradually as long as rock specimens have linear elasticity in the compression deformation stage. Besides, the Kaiser effect is true all the time no matter how many loading-unloading cycles. The experimental results (Figure 11) demonstrate that the Felicity ratio of red sandstone specimens is larger than 1.0 in the first $2 \sim 3$ cycles, indicating that the Kaiser effect is true. This stage is the elastic deformation stage of rock specimens, where rock specimens have good memory functions. After the $3 \sim 4$ cycles (cyclic load peak is about 1/3 1/2 of comprehensive strength of specimens), rock damages intensify, AE phenomena become active, the Felicity ratio decreases to smaller than 1.0, and the Felicity effect is true with the increase of loads, indicating that the Kaiser effect of rock materials has certain limitations. After rock elasticity weakens, the Kaiser effect becomes false. This reflects that the current stress level is lower than the load peak of the previous cycle when $\mathrm{AE}$ quantities of the current cycle reaches $\mathrm{AE}$ quantities corresponding to the load peak of the previous cycle. This is because the plasticity of rocks becomes the leading property under high loads.

Compared to the elastic stage, internal crack structure becomes very unstable when rocks have plastic deformation under high loads, mainly manifested by development and expansion of induced cracks. Except for loads, microcrack expansion is also influenced by crack separation and crack connection. Therefore, density, intensity, and quantity of cracks as well as plasticity are high under high loads, but deformation recovery degree is low. Cracks and the cracking structure could not reach the stability or equilibrium state, so they could not remember corresponding stress states. Rock deformation could not be recovered completely after unloading and there is certain residual strain. Larger residual strain of rock specimens means more induced cracks in rocks and more induced AE quantities. Under high loads, small load changes can facilitate development of many cracks, thus producing abundant $\mathrm{AE}$ events. The $\mathrm{AE}$ quantities induced by unit load growth are significantly higher than $\mathrm{AE}$ quantities induced by unit load growth in the elastic stage. Therefore, in the second loading process, $\mathrm{AE}$ quantities can exceed that at the load peak of the previous cycle before the current load level reaching the load peak of the previous cycle. This means that the rock strength declines, so the Felicity ratio decreases to smaller than 1 . With the increase of loads, the Felicity ratio decreases gradually on the whole, which is caused by influences of plastifying rate of rock specimens. Variations of the Felicity effect of $\mathrm{AE}$ phenomena under linear-elastic model and elastic-plastic model conditions are shown in Figure 12(a). With the increase of loading-unloading cycles, rock damages accumulate continuously until buckling failure of rock specimens. Rocks present different AE phenomena in different elastic-plastic stages. The elastic stage and plastic stage of the compression deformation stage of rock specimens are corresponding to the Kaiser effect and Felicity effect. The Kaiser effect is true in the elastic stage, while the Felicity effect is true in the plastic stage. Therefore, elastic and plastic stages in compression deformation of rock specimens could be identified generally according to variations of the Felicity ratio.

According to experimental results, the loading rate and unloading rate influence variations of the Felicity ratio slightly. Based on fitting curves of the Felicity ratio in Figures 11(a)-11(f), the Felicity ratio of red sandstone specimens decreases gradually in the elastic stage and increases slightly in the plastic stage when the loading rate increases gradually, but the unloading rate is kept constant. The fitting curves of the Felicity ratio in Figures 11(g)-11(l) reveal that the Felicity ratio of red sandstone specimens deceases gradually in the elastic stage and keeps basically same in the plastic stage when the unloading rate increases gradually, but the loading rate remains unchanged. The growth model of AE rings of rock specimens under low and high loading rates is shown in Figure 13. 

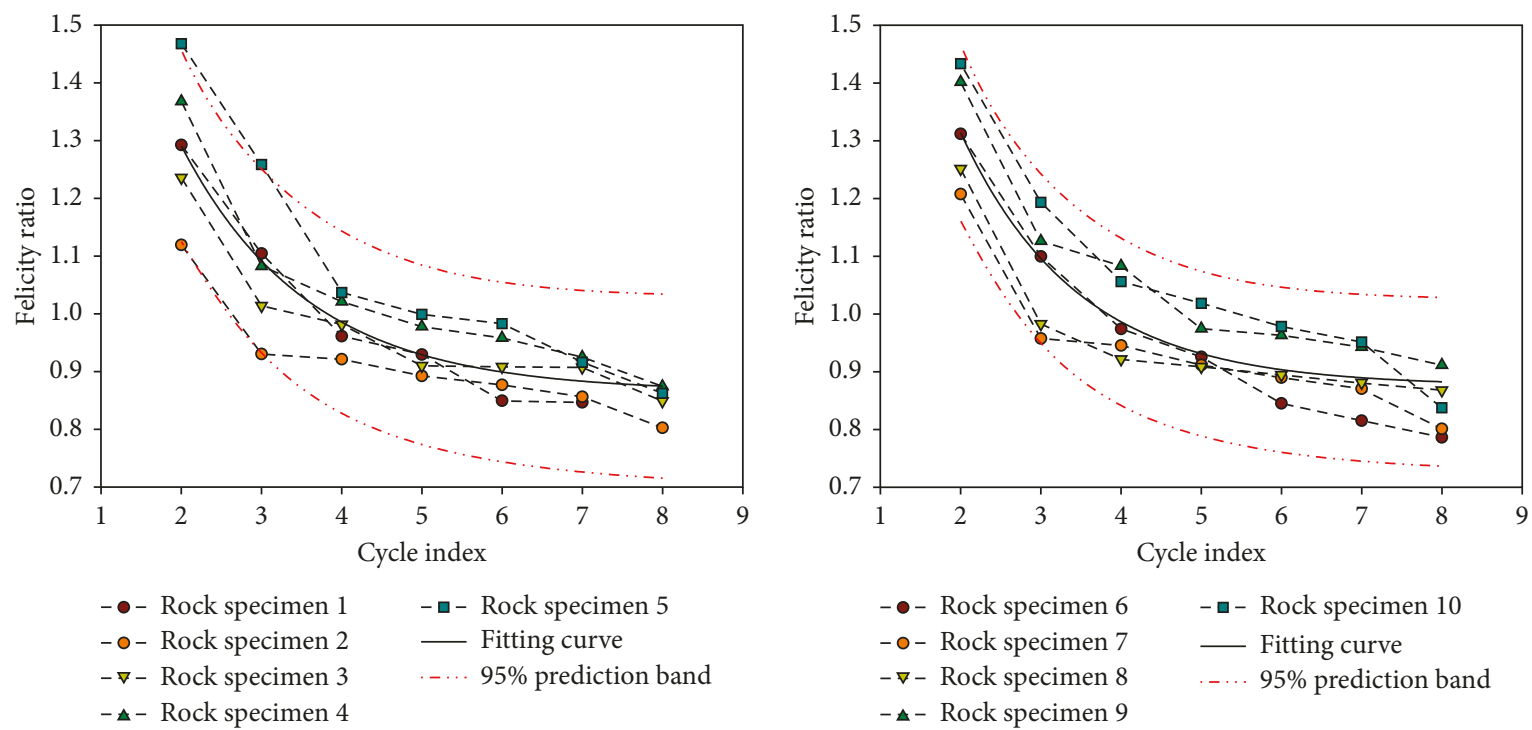

(a)
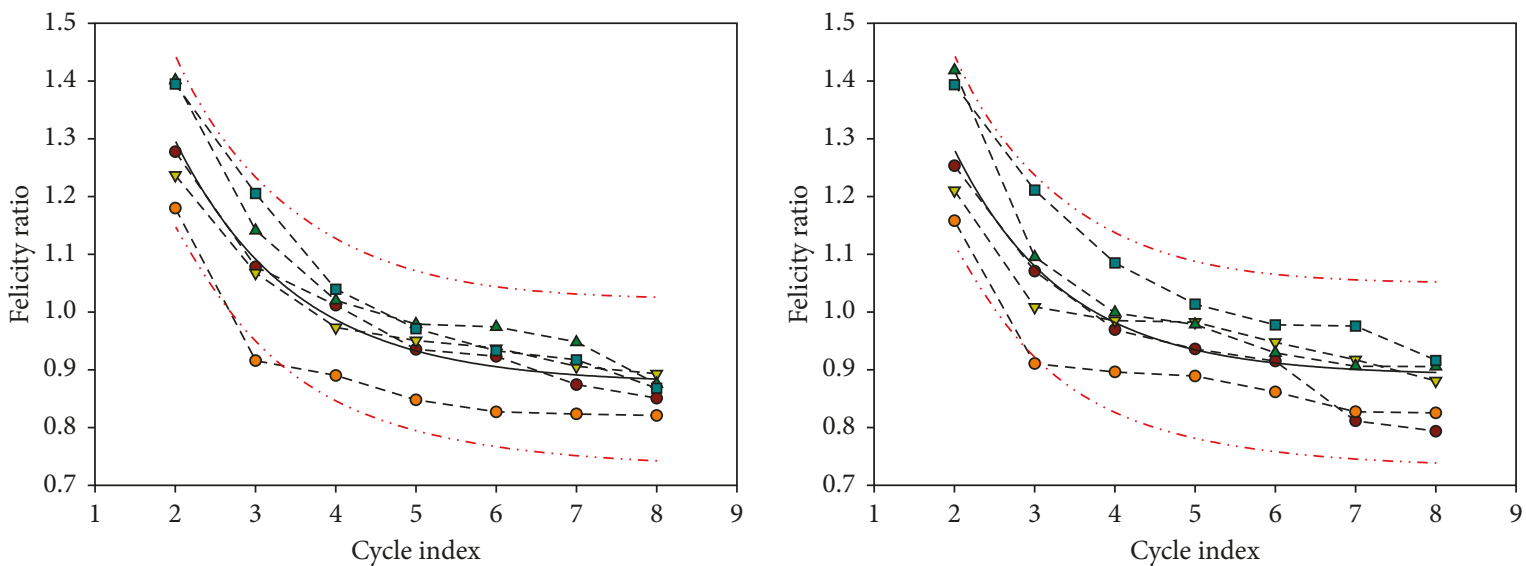

- - Rock specimen $11 \quad$ - - Rock specimen 15

- o- Rock specimen 12 - Fitting curve

$-\nabla$ - Rock specimen $13 \quad \ldots 95 \%$ prediction band

- $\mathbf{-}$ - Rock specimen 14

(c)

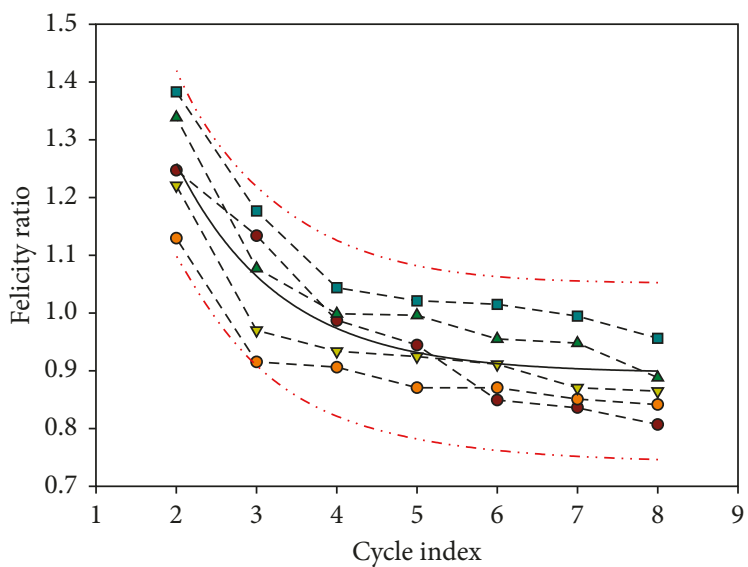

- - Rock specimen 21

- - Rock specimen 25

- o- Rock specimen 22

- Fitting curve

$-\nabla$ - Rock specimen 23 $95 \%$ prediction band

- $\mathbf{-}$ - Rock specimen 24

(e)

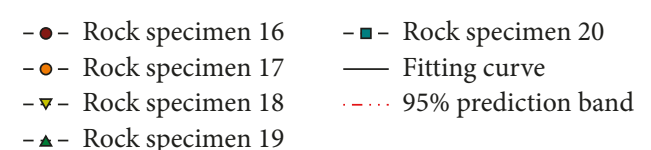

(d)
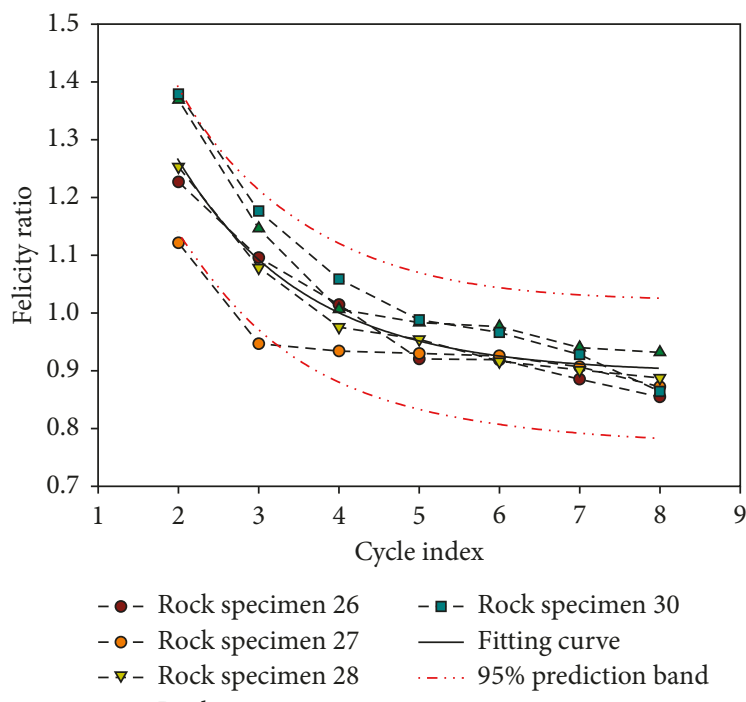

- $\mathbf{-}$ - Rock specimen 29

FIGURE 11: Continued. 

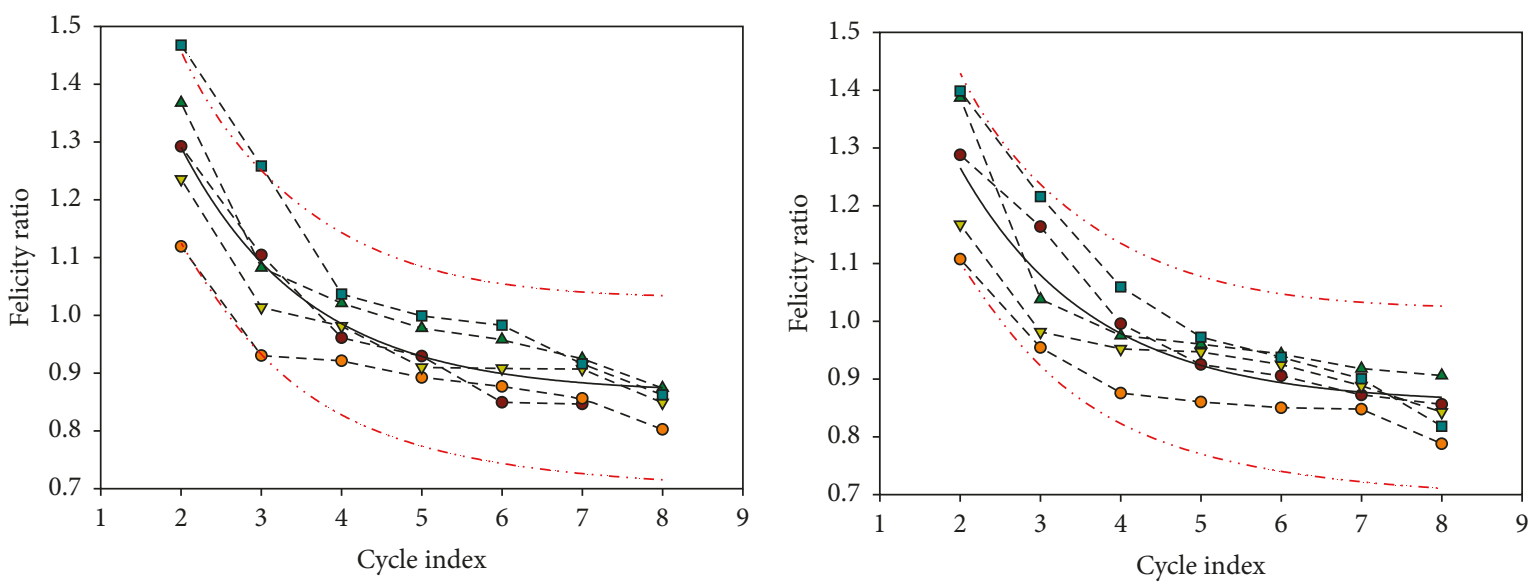

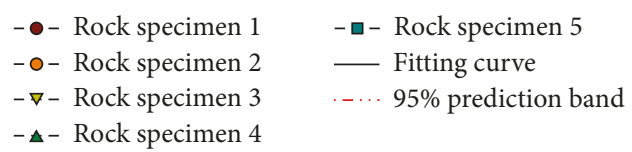

(g)

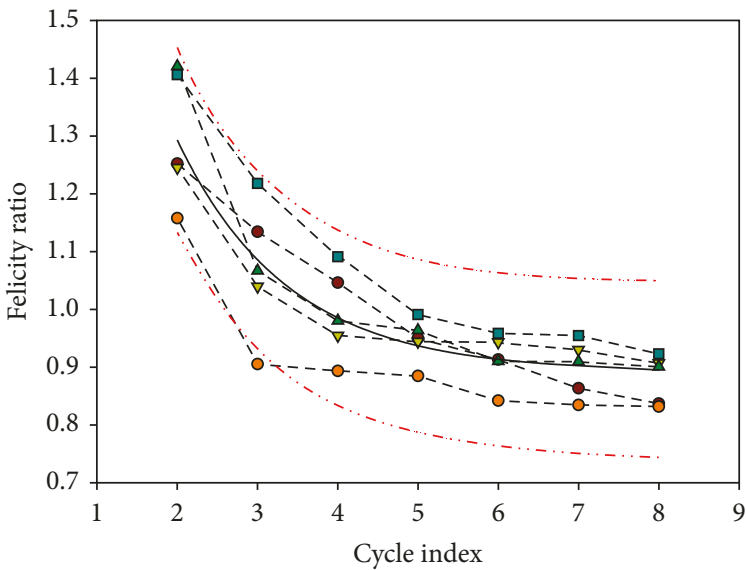

- - Rock specimen 36

- o- Rock specimen 37

$-\nabla$ - Rock specimen 38

- $\Delta$ - Rock specimen 39

(i)

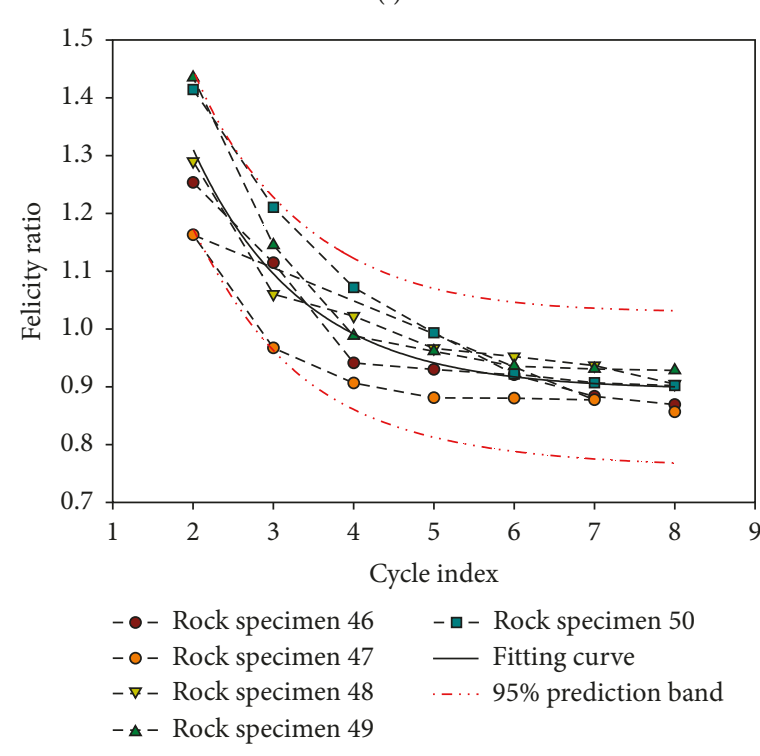

(k)

\section{- - Rock specimen 40 \\ - Fitting curve \\ . ... 95\% prediction band}

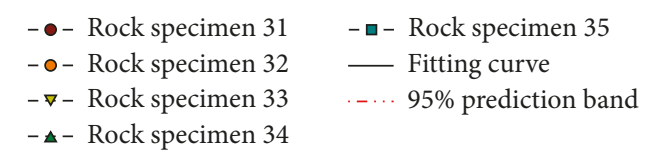

(h)

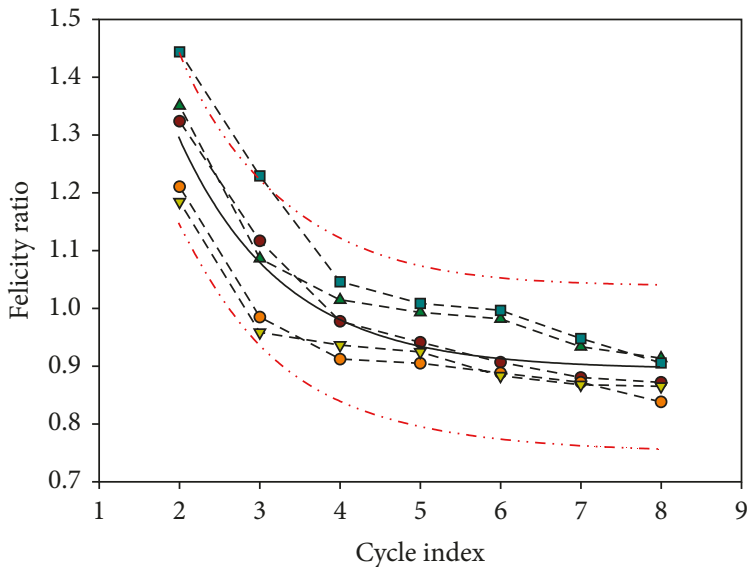

$$
\begin{array}{ll}
\text { - } \bullet \text { - Rock specimen } 41 & -\bullet-\text { Rock specimen } 45 \\
\text { - } \bullet-\text { Rock specimen } 42 & - \text { Fitting curve } \\
-\nabla-\text { Rock specimen } 43 & -\cdots 95 \% \text { prediction band } \\
-\star-\text { Rock specimen } 44 &
\end{array}
$$

(j)

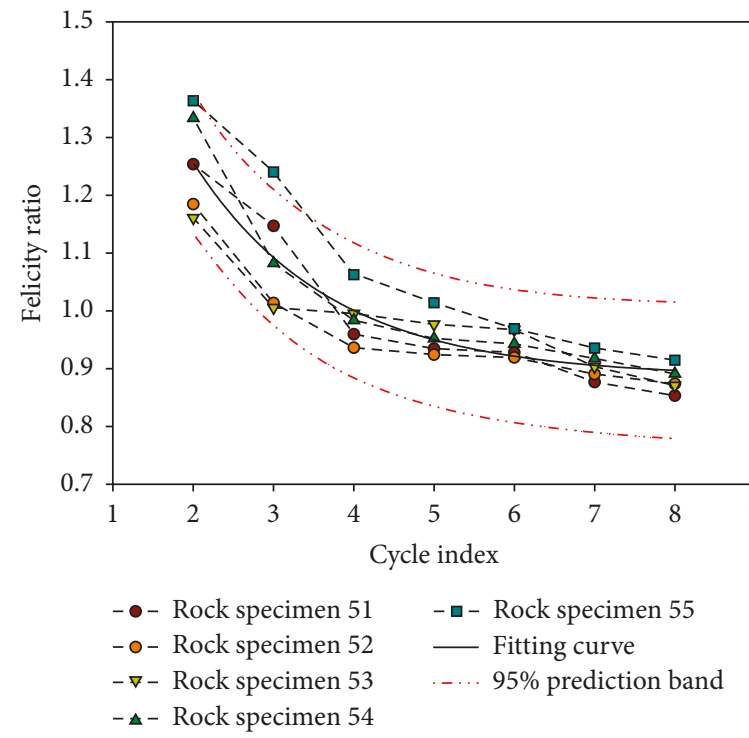

(1)

FIgURE 11: Variation of the rock Felicity ratio with the increasing loading stress. 


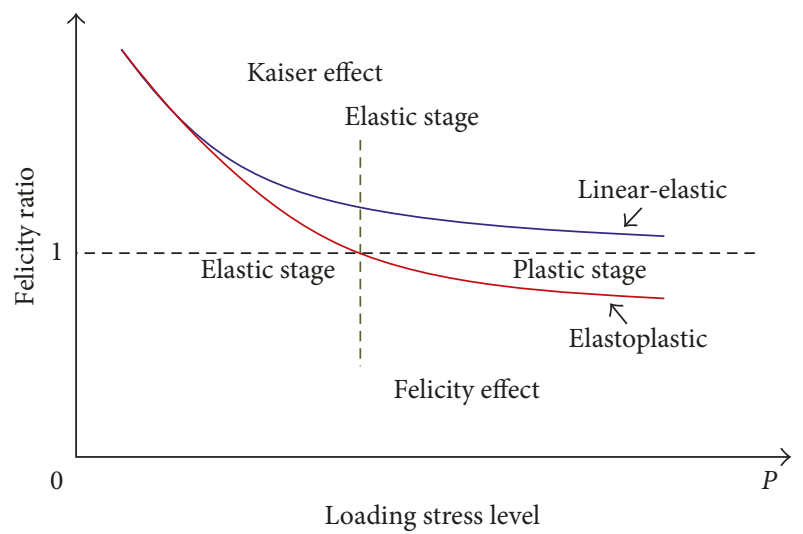

(a)

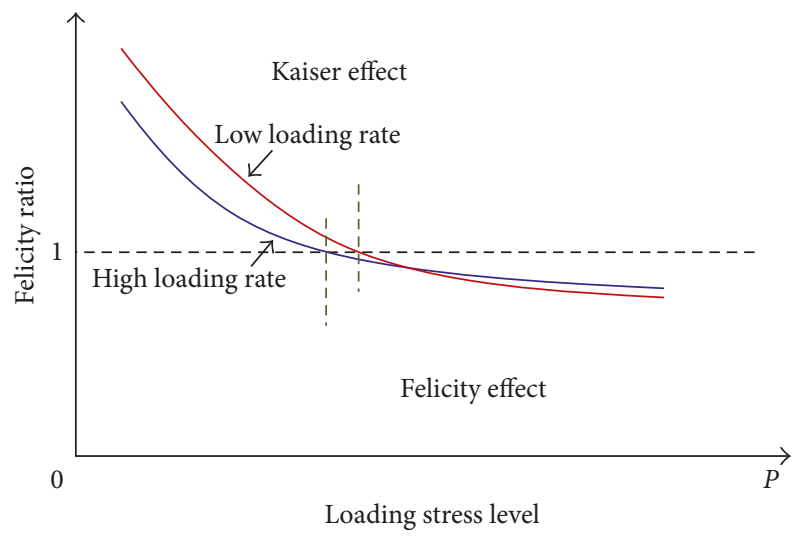

(b)

FIGURE 12: Evolution of the rock Felicity effect under uniaxial cyclic loading-unloading compression conditions. (a) AE Felicity effect in linear-elastic model and elastic-plastic model; (b) influences of $\mathrm{AE}$ Felicity effect under low and high loading rates.

In the elastic stage of compression deformation of rock specimens, when the first loading-unloading cycle reaches the same peak load level $p_{1}$ under different loading rates $\operatorname{Lr}_{1}$ and $\operatorname{Lr}_{2}\left(\operatorname{Lr}_{1}<\operatorname{Lr}_{2}\right), Q_{11}$ and $Q_{21}$ of $\mathrm{AE}$ rings have a relationship that $Q_{11}>Q_{21}$ according to the experimental results that "the lower the loading rate, the slower the damage development and the more the AE rings; otherwise, the higher the loading rate, the quicker the damage development and the fewer the AE rings." Section $0-p_{1}$ of the second loading-unloading cycle is the fatigue damage process of rock specimens under same loading conditions. According to experimental results, $Q_{12.1}$ and $Q_{22.1}$ of $A E$ rings produced by repeated loading processes have the relationship $Q_{12.1}>Q_{22.1}$. Besides, $\left(Q_{11}-Q_{12.1}\right)-\left(Q_{21}-Q_{22.1}\right)$ $>0$. In the section $p_{1}-p_{2}$ of the second cycle, AE quantities under two loading rates increase significantly based on the growth pattern of $\mathrm{AE}$ rings. In contrast, the $\mathrm{AE}$ rings under low loading rate $\left(Q_{\mathrm{ae}_{12}}\right)$ are higher than $\mathrm{AE}$ rings under high loading rate $\left(Q_{\mathrm{ae}_{22}}\right)$ when the load increases to the same load peak $p_{2}\left(p_{2}=p_{1}+\Delta\right)$. Since the loading rate will influence AE phenomena of rock specimens more seriously with the increase of loads, the gap between AE quantities becomes wider and wider: $\left(\mathrm{Q}_{\mathrm{ae}_{12}}-\mathrm{Q}_{\mathrm{ae}_{22}}\right)>\left(\mathrm{Q}_{\mathrm{ae}_{11}}-\mathrm{Q}_{\mathrm{ae}_{21}}\right)$. Under the low

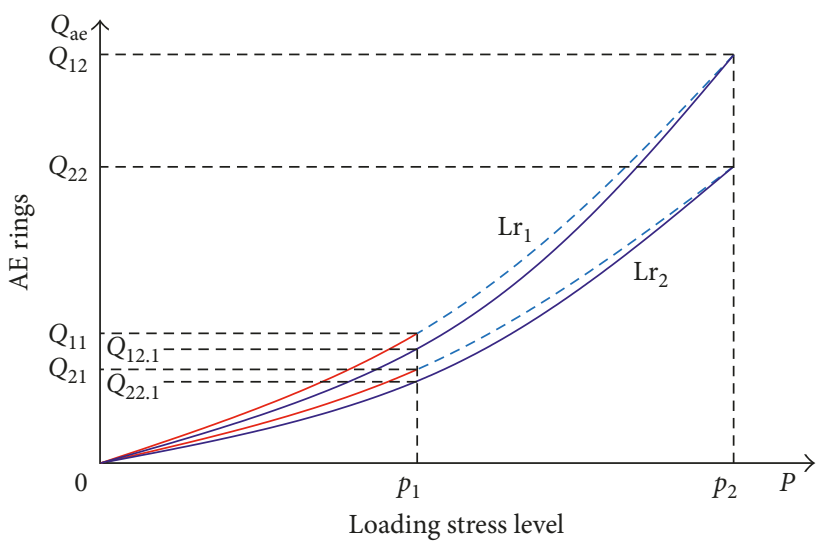

FIgURE 13: Growth model of rock AE rings under low and high loading rates.

loading rate $\left(\operatorname{Lr}_{1}\right)$, AE quantities in the $p_{1}-p_{2}$ section increases from $Q_{12.1}$ to $Q_{11}$ and the loads shall be increased by $\Delta p_{12.1}$ accordingly. The corresponding Felicity ratio is

$$
\mathrm{Fr}_{12}=\frac{p_{1}+\Delta p_{12.1}}{p_{1}}=1+\frac{\Delta p_{12.1}}{p_{1}}
$$

The situation under high loading rate $\left(\mathrm{Lr}_{2}\right)$ is similar with that under the low loading rate $\left(\operatorname{Lr}_{1}\right)$. When $\mathrm{AE}$ rings increase from $Q_{22.1}$ to $Q_{21}$, the current stress level must increase from $p_{1}$ to $p_{1}+\Delta p_{22.1}$. Accordingly, the Felicity ratio is

$$
\mathrm{Fr}_{22}=\frac{p_{1}+\Delta p_{22.1}}{p_{1}}=1+\frac{\Delta p_{22.1}}{p_{1}}
$$

By comparing $\mathrm{Fr}_{12}$ and $\mathrm{Fr}_{22}$, the magnitude difference is mainly determined by difference between $\Delta p_{12.1}$ and $\Delta p_{22.1}$. According to experimental results of $\mathrm{AE}$ phenomena of rock specimens, the higher the loading rate, the higher consistence of $\mathrm{AE}$ counts changes between the current cycle and the previous cycle under the same load level, that is, $Q_{21}-Q_{22.1} \approx 0$. In the elastic compression deformation stage of rock specimens, internal structures change under stress conditions. Compared to low loading rate, high loading rate changes loads (increase, decrease, transfer, or removal) before the internal microstructure of rock specimens makes corresponding responses to the stress load. Reponses of the rock internal structure to stress load lag to some extent. Such lagging intensifies under high loading rate. With the increase in loading rate, internal microstructure change in unit time is relatively small. Intensifying and large-scale failures are often caused directly after the loads exceed the ultimate bearing capacity of the microstructure. In this case, it needs a small stress increment for the AE rings in the current cycle to reach $\mathrm{AE}$ rings corresponding to load peak of the previous cycle. Such stress increment shall be lower than stress increment under low loading rate to some extent. Therefore, $\Delta p_{22.1}<\Delta p_{12.1}$. With respect to the felicity effect of $\mathrm{AE}$ phenomena of rock specimens, $\mathrm{Fr}_{12}>\mathrm{Fr}_{22}$, which reflects that with the gradual increase of loading rate, the Felicity ratio decreases continuously in the elastic stage of compression deformation. Furthermore, with the increase of 
loading rate, the occurrence frequency of strong $\mathrm{AE}$ events increases, internal principal crack expands, and principal failure intensifies. Rocks often enter into the plastic stage in advance. The Felicity effect is manifested early. In the plastic deformation stage of rocks, the Felicity ratio changes slightly with the loading rate, which is related with complexity of plastic failure and anisotropism of rocks. However, internal cracks of rocks develop and expand completely under low loading rate and more $\mathrm{AE}$ rings will be produced under same load level, so AE counts can reach to the $\mathrm{AE}$ counts at the load peak of the previous cycle early. Therefore, the Felicity ratio is relatively smaller under low loading rate. Based on experimental data analysis, the Felicity effect of AE phenomena in the plastic deformation stage of rocks increases slightly with the increase of loading rate. Influences of the Felicity effect of AE phenomena under low and high loading rates are shown in Figure 12(b).

\section{Conclusions}

(1) In the uniaxial loading-unloading cycles, AE rings of rock specimens are positively correlated with load level and will fluctuate to some extent in the short-time domain. AE phenomena will occur during the compression deformation of rock specimens. Under the cyclic equivalent loading effect, $\mathrm{AE}$ rings decrease with the increase of fatigue damages, but achieve exponential growth with the linear growth of loads. Under cyclic equivalent unloading, AE rings increase with the increase of fatigue damages under low stress level, but decrease with the increase of fatigue damages under high stress level. Compression rock specimens will experience multiple expansions and connections of principal crack with different intensities at the moment of complete buckling failure. Development, expansion, and connection of principal cracks take a total of about $60 \mathrm{~ms}$. The duration of omen failure state is about 3 times that of the complete failure state. During this period, the AE signal has wide frequency band (mainly concentrating between $1 \mathrm{kHz}$ and $35 \mathrm{kHz}$ ) and contains rich frequency components. The principal frequency is about $20 \mathrm{kHz}$.

(2) Growths of loading rate and unloading rate will decrease total AE rings of rock specimens gradually throughout the compression deformation process. Particularly, growth of loading rate decreases total AE rings more significantly. The total $\mathrm{AE}$ rings have an approximate negative linear correlation with loading and unloading rates. Given fixed unloading rate and when the loading rate increases gradually, the maximum $\mathrm{AE}$ rings and total $\mathrm{AE}$ rings of rocks in the single loading-unloading cycle under same load level, total $\mathrm{AE}$ rings in the loading process, and total $\mathrm{AE}$ rings in the unloading process all decrease gradually. Total AE rings in the loading process reduce the most, showing an approximately multiple reduction trend. Under low loading rate, full development and expansion of abundant induced microcracks reduce the compressive strength of rocks, thus making rocks suffer complete plastic buckling failure of rocks under low loads. Under high loading rate, development and expansion of relatively large induced microcracks in rocks are main deformation and failure modes, manifested by increasing intensity of some AE events and gradually weakening $\mathrm{AE}$ phenomena on the whole. Particularly, rocks begin to represent brittle failure behaviors when the loading rate is higher than $2.0 \mathrm{kN} / \mathrm{s}$. Given fixed loading rate and when unloading rate increases gradually, total $\mathrm{AE}$ counts in the unloading process of the single loading-unloading cycle are influenced mostly and decrease gradually. Under high unloading rate, internal microcracks of rock mass are difficult to be developed and expanded completely in the short period, thus weakening and reducing $\mathrm{AE}$ phenomena in the cyclic compression deformation stage. When $\mathrm{Ur} \geq 3.0$, AE phenomena in the final compression deformation stage enhance continuously. Changes of loading rate and unloading rate will influence rock $\mathrm{AE}$ characteristics directly to some extent. The loading process is the active period of $\mathrm{AE}$ phenomena, which reveals that the loading process influences deformation and failure of rock specimens more significantly.

(3) Rock specimens have good memory in the elastic compression deformation stage. Rock AE characteristics represent the Kaiser effect. When the cyclic load peak reaches 1/3 1/2 UCS, plasticity of rocks becomes the leading attribute. The Felicity effect of AE begins to be represented and intensifies gradually with the continuous growth of cyclic stress load level. Difference of the Felicity effect of different rock specimens decreases gradually with the continuous growth of cyclic stress load. AE rings induced by unit load increment in the plastic stage of rocks are far higher than AE rings in the elastic stage. The elastic stage and plastic stage of compression deformation of rock specimens could be identified generally according to changes of the Felicity ratio. The Felicity ratio is influenced slightly by the loading rate and unloading rate. As the loading rate increases gradually, the Felicity ratio of red sandstone specimens reduces in the elastic stage and increases slightly in the elastic stage. As the unloading rate increases gradually, the felicity ratio of red sandstone specimens decreases gradually in the elastic stage, but keeps constant in the plastic stage. These are closely related with the lagging responses of internal structure to stress load. Such lagging effect intensifies when the loading rate increases.

\section{Conflicts of Interest}

The authors declare that they have no conflicts of interest.

\section{Authors' Contributions}

Mingwei Zhang, Qingbin Meng, Shengdong Liu, and Nong Zhang conceived and designed the experiments; 
Mingwei Zhang, Qingbin Meng, and Deyu Qian performed the experiments; Mingwei Zhang, Qingbin Meng, Shengdong Liu, Deyu Qian, and Nong Zhang analyzed the data; Mingwei Zhang wrote the paper.

\section{Acknowledgments}

The authors thank the National Key R\&D Program of China (no. 2016YFC0600900), the National Natural Science Foundation of China (nos. 51504237, 51704277, and 51674244), and the China Postdoctoral Science Foundation (no. 2017M621874) for providing financial and general supports for this research.

\section{References}

[1] A. Lavrov, "The Kaiser effect in rocks: principles and stress estimation techniques," International Journal of Rock Mechanics and Mining Sciences, vol. 40, no. 2, pp. 151-171, 2003.

[2] Z. Moradian, H. H. Einstein, and G. Ballivy, "Detection of cracking levels in brittle rocks by parametric analysis of the acoustic emission signals," Rock Mechanics and Rock Engineering, vol. 49, no. 3, pp. 785-800, 2016.

[3] F. Gao, D. Stead, and H. Kang, "Numerical simulation of squeezing failure in a coal mine roadway due to mining-induced stresses," Rock Mechanics and Rock Engineering, vol. 48, no. 4, pp. 1635-1645, 2015.

[4] H. S. Jang, Y. S. Ma, and B. A. Jang, "Acoustic emission property and damage estimation of rock due to cyclic loading," Engineering Geology, vol. 17, no. 16, pp. 235-244, 2006.

[5] E. Proverbio, "Evaluation of deterioration in reinforced concrete structures by AE technique," Materials and Corrosion, vol. 62, no. 2, pp. 161-169, 2011.

[6] C. Li and E. Nordlund, "Experimental verification of the Kaiser effect in rocks," Rock Mechanics and Rock Engineering, vol. 26, no. 4, pp. 333-351, 1993.

[7] V. Rudajev, J. Vilhelm, and T. Lokajicek, "Laboratory studies of acoustic emission prior to uniaxial compressive rock failure," International Journal of Rock Mechanics and Mining Sciences, vol. 37, no. 4, pp. 699-704, 2000.

[8] A. Lavrov, "Kaiser effect observation in brittle rock cyclically loaded with different loading rates," Mechanics of Materials, vol. 33, no. 11 , pp. 669-677, 2001.

[9] P. V. Nikolenko and V. L. Shkuratnik, "Acoustic emission in composites and applications for stress monitoring in rock masses," Journal of Mining Science, vol. 50, no. 6, pp. 1088-1093, 2014.

[10] J. Fan, J. Chen, D. Jiang, A. Chemenda, J. Chen, and J. Ambre, "Discontinuous cyclic loading tests of salt with acoustic emission monitoring," International Journal of Fatigue, vol. 94, pp. 140-144, 2017.

[11] D. Elmo, D. Stead, E. Eberhardt, and A. Vyazmensky, “Applications of finite/discrete element modeling to rock engineering problems," International Journal of Geomechanics, vol. 13, no. 5, pp. 565-580, 2013.

[12] T. Ishida, T. Kanagawa, and Y. Kanaori, "Source distribution of acoustic emissions during an in-situ direct shear test: implications for an analog model of seismogenic faulting in an inhomogeneous rock mass," Engineering Geology, vol. 110, no. 3-4, pp. 66-76, 2010.

[13] B. Huang and J. Liu, "The effect of loading rate on the behavior of specimens composed of coal and rock," International Journal of Rock Mechanics and Mining Sciences, vol. 61, pp. 23-30, 2013.

[14] P. Lukaszewski, "Development of fracture processes in silesian carboniferous sandstones," Geological Quarterly, vol. 47, no. 1, pp. 29-37, 2010.
[15] Y. Zhao and Y. Jiang, "Acoustic emission and thermal infrared precursors associated with bump-prone coal failure," International Journal of Coal Geology, vol. 83, no. 1, pp. 11-20, 2010.

[16] S. Wang, D. Elsworth, and J. Liu, "Permeability evolution in fractured coal: the roles of fracture geometry and watercontent," International Journal of Coal Geology, vol. 87, no. 1, pp. 13-25, 2011.

[17] D. V. Yakovlev, T. I. Lazarevich, and S. V. Tsirel, "Natural and induced seismic activity in Kuzbass," Journal of Mining Science, vol. 49, no. 6, pp. 862-872, 2013.

[18] M. Alber, R. Fritschen, M. Bischoff, and T. Meier, "Rock mechanical investigations of seismic events in a deep longwall coal mine," International Journal of Rock Mechanics and Mining Sciences, vol. 46, no. 2, pp. 408-420, 2009.

[19] D. Lamich, M. Marschalko, I. Yilmaz et al., "Geodetic monitoring of roads as a tool for determination of hazard zones in areas influenced by deep coal mining," Bulletin of Engineering Geology and the Environment, vol. 75, no. 3, pp. 1033-1044, 2016.

[20] R. Yuan and Y. Li, "Theoretical and experimental analysis on the mechanism of the Kaiser effect of acoustic emission in brittle rocks," Journal of University of Science and Technology Beijing, Mineral, Metallurgy, Material, vol. 15, no. 1, pp. 1-4, 2008.

[21] H. Wang, T. P. Chang, and J. J. Hung, "Determining the cyclic strength of geomaterials under low frequency cyclic loading with acoustic emission," Journal of Marine Science and Technology, vol. 18, no. 6, pp. 837-847, 2010.

[22] X. Fu, Q. Xie, and L. Liang, "Comparison of the Kaiser effect in marble under tensile stresses between the Brazilian and bending tests," Bulletin of Engineering Geology and the Environment, vol. 74, no. 2, pp. 535-543, 2015.

[23] Q. Meng, M. Zhang, L. Han, H. Pu, and T. Nie, "Effects of acoustic emission and energy evolution of rock materials under the uniaxial cyclic loading and unloading compression," Rock Mechanics and Rock Engineering, vol. 49, no. 10, pp. 3873-3886, 2016.

[24] D. J. Holcomb and L. S. Costin, "Detecting damage surfaces in brittle materials using acoustic emissions," Journal of Applied Mechanics, vol. 53, no. 3, pp. 536-544, 1986.

[25] Y. Jin, Z. Qi, M. Chen, G. Zhang, and G. Xu, "Time-sensitivity of the Kaiser effect of acoustic emission in limestone and its application to measurements of in-situ stress," Petroleum Science, vol. 6, no. 2, pp. 176-180, 2009.

[26] S. A. Shapiro and C. Dinske, "Violation of the Kaiser effect by hydraulic-fracturing-related microseismicity," Journal of Geophysics and Engineering, vol. 4, no. 4, pp. 378-383, 2007.

[27] Y. Wu, Z. P. Shao, F. Wang, and G. L. Tian, "Acoustic emission characteristics and felicity effect of wood fracture perpendicular to the grain," Journal of Tropical Forest Science, vol. 26, no. 4, pp. 522-531, 2014.

[28] A. D. Papargyris, R. G. Cooke, S. A. Papargyri, and A. I. Botis, "The acoustic behaviour of bricks in relation to their mechanical behaviour," Construction and Building Materials, vol. 15, no. 7, pp. 361-369, 2001. 


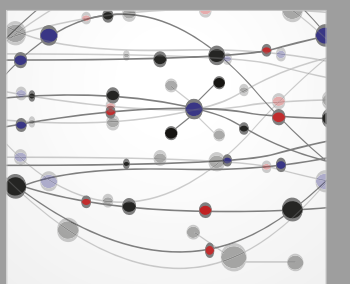

The Scientific World Journal
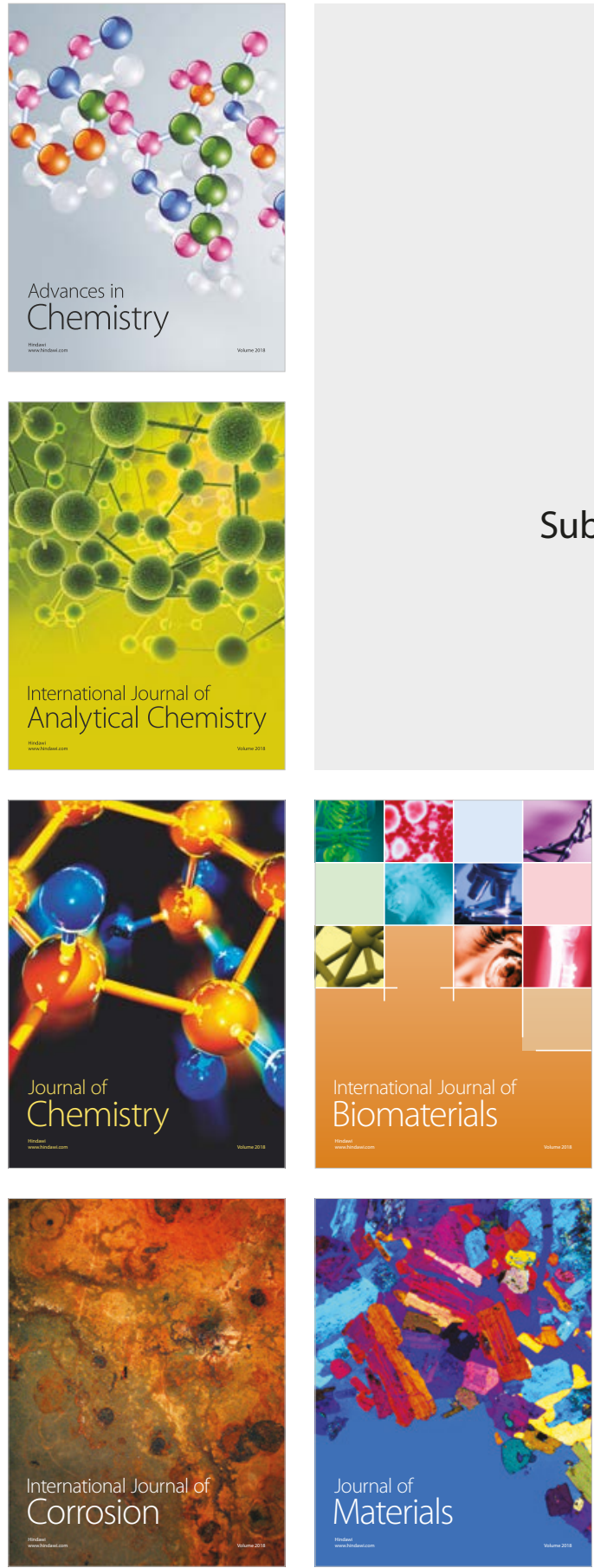

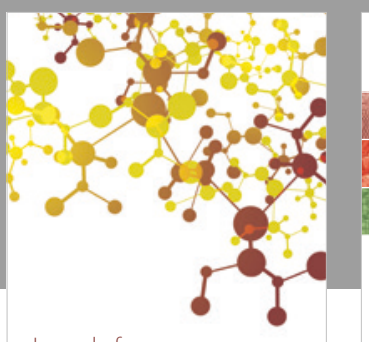

Journal of

Applied Chemistry
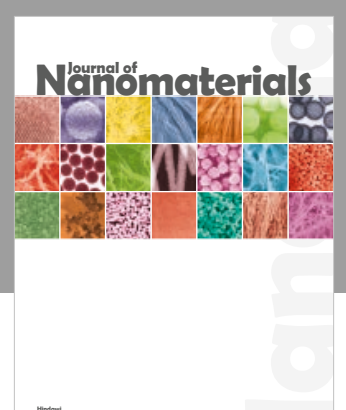

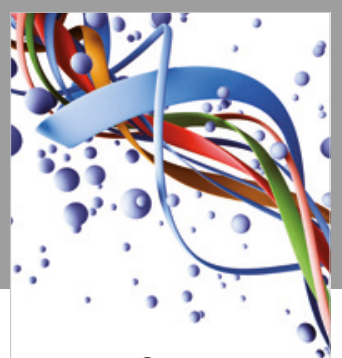

Scientifica

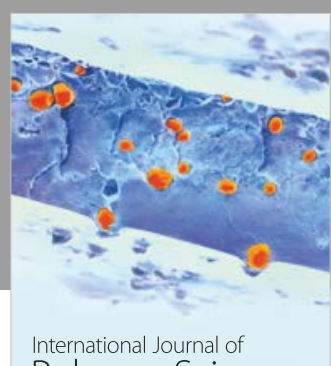

Polymer Science

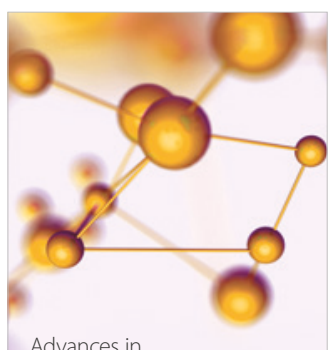

Physical Chemistry
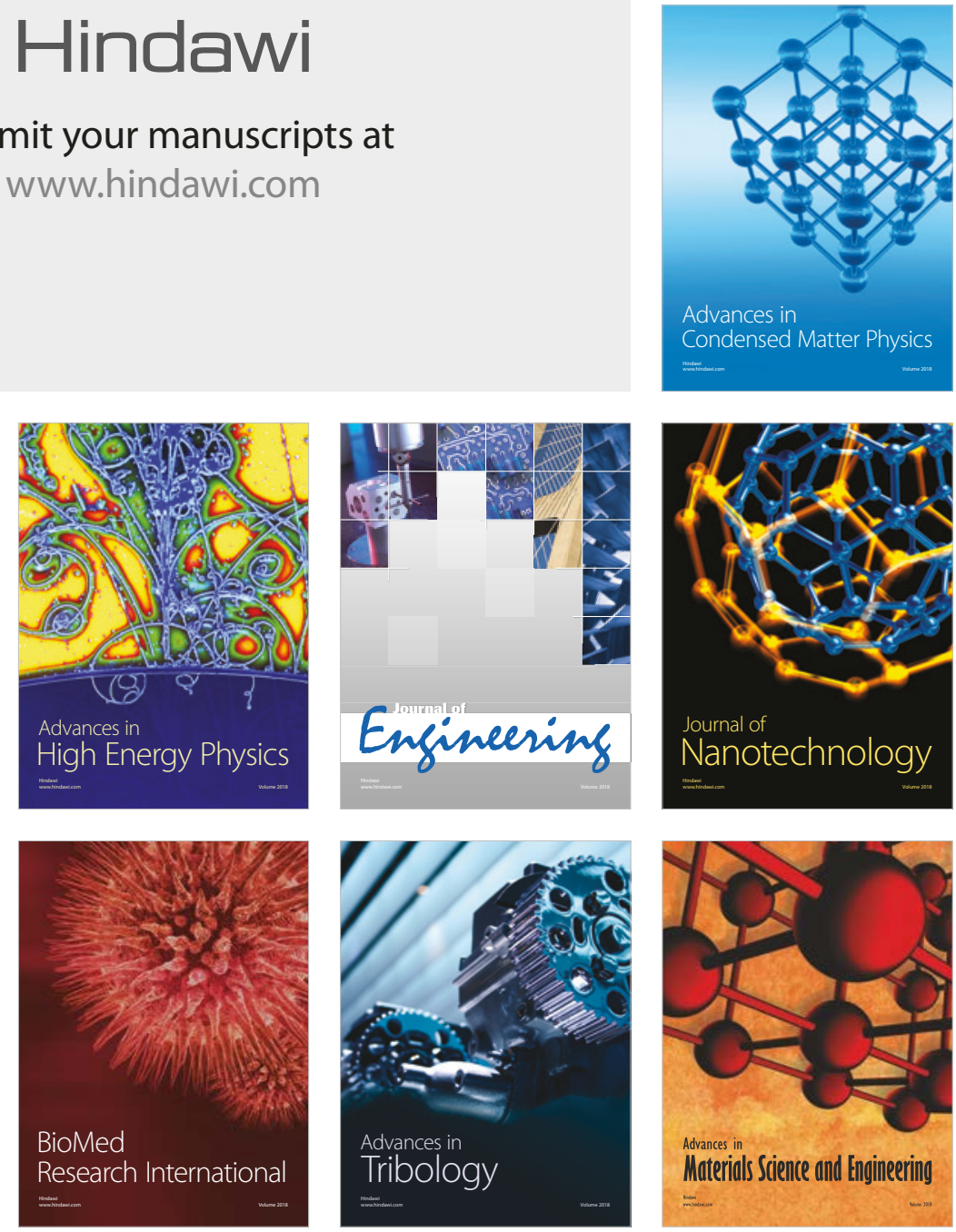